\title{
Visions of Research in Music Education
}

Volume 20 Special Edition: A Tribute to Jeanne Bamberger

2012

Developing Musical Structures: Going Beyond the Simples

Jeanne Bamberger

Follow this and additional works at: https://opencommons.uconn.edu/vrme

Recommended Citation

Bamberger, Jeanne (2012) "Developing Musical Structures: Going Beyond the Simples," Visions of Research in Music Education: Vol. 20 , Article 14.

Available at: https://opencommons.uconn.edu/vrme/vol20/iss1/14 


\title{
Musical Transformation and
}

\section{Musical Intuition}

\author{
Eleven Essays \\ in honor of \\ DAVID LEWIN
}

EDITED BY

Raphael Atlas and Michael Cherlin

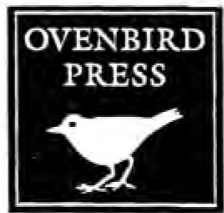


Visions of Research in Music Education, Vol. 20 [2012], Art. 14

\title{
DEVELOPING MUSICAL STRUCTURES: GOING BEYOND THE SIMPLES
}

\author{
Jeanne Bamberger
}

In this essay I trace the process through which two (imaginary) students develop their hearings of a Beethoven minuet. The title I have given the essay is meant to be a pun: as the students' hearings develop, they come to hear the minuet as a "developing musical structure"; at the same time, and through this process, they are also necessarily developing their own mental "musical structures." And as the students learn, they come to hear the minuet as "learning," too.

What does it mean to develop a "hearing" of a work, and how, indeed, is it possible to describe another's hearing of a work at all? The questions raise a cluster of rather knotty problems. An individual's hearing is, perhaps paradoxically, a silent affair, so how can anyone know-how can we hear the hearing another has made? An out-loud, verbal description provides clues, but only impoverished clues, for descriptions are always influenced by the terms - the "units of description"-that the hearer has available. So we need to ask: what are the differences between, on one hand, the kinds of entities and relations that can be captured by the units of description that an individual has available, and on the other, the kinds of entities and relations that "occupy" the hearer's "units of perception"-those that an individual constructs in action, on the spot. And, of course, even if we could gain access to another's hearing (or indeed to our own), could we agree on what it might mean to make an "appropriate hearing" in contrast to, say, an inappropriate hearing?

Without trying to answer these questions (but still bearing them in mind), I shall argue that $a$ hearing is a performance. That is, what the hearer seems simply to find in the music, is actually a process of instant perceptual problem solving - an active process of sense-making something like that evoked by the comments of the painter, Ben Shahn:

So one must say that painting is both creative and responsive. It is an intimately communicative affair between the painter and his painting, a conversation back and forth, the painting telling the painter even as it receives its shape and form. $(1957,49)$

A hearing, then, may seem to be instantaneous, ineluctable, but it is, in fact, a process in which the mind is actively engaged in organizing incoming sensory material-an active play between the tacit, often unnoticed mental activities that an individual brings to bear, and the yet to be organized stuff "out there." What we hear depends on what we are able to think of to hear-even though we are quite unaware that thinking is going on at all. But by "organizing" I don't mean to suggest some kind of "decoding" process, as if the incoming material has already been segmented, and these entities labeled or otherwise symbolically "encoded." Indeed, I will emphasize that it is exactly because sound/time phenomena do not come already structured, but rather hold the potential for being structured, that different hearings are possible and that hearings can develop. As Israel Rosenfield says, "We perceive the world without labels, and we can label it only when we have decided how its features should be organized."1 $(1989,187)$ 
But to say this raises another problem and it is to this that much of what follows is addressed: If we are actively organizing incoming phenomena as they occur in time, what might be the immediately functioning constraints on these generative organizing processes; and how do these constraints evolve, develop, and change? Or putting it another way: in our creative and responsive "conversations back and forth" with material out there, what are the mental constraints that shape our momentary potential for making coherence and meaning in particular ways? ${ }^{2}$ In short, what are the mental organizing constraints on the hearings that individuals make and how do these differ from one individual to another?

I will argue that these constraints (and the bases for instant perceptual problem solving) initially derive from repeated exposure to a relatively small set of pitch-time relations common to the music of our culture and associated with its sense-making. In constructing a hearing of an unfamiliar work, we actively seek out these organizing pitch-time relations, constructing them anew as features which we expect to find as giving music its coherence. I refer to these common pitch-time relations as "simples," and I will show that on a first hearing, students' generative organizing constraints are initially limited to just those associated with "simples." I use the term simples in two senses:

1) to refer to tunes and rhythms that we all sang and clapped as children. These actual tunes and rhythms that most of us learned in the natural course of growing up, I call the Simples of our culture. Of these, I think of "Twinkle Twinkle Little Star" as the prototypical Simple - a kind of "ur-tune";

2) to refer to what I will call "structural simples." These are the "generative primitives," the small set of recurring pitch-time relations that, through cultural evolution, we have come to associate with coherence-relations shared by the common folk music of our culture, and by and large by all of the art music from at least Bach to Brahms. These I will continue to call structural simples.

The two come together in that structural simples are expressed in the most clear and unadorned fashion by our familiar Simples. Thus I argue that structural simples, as they are embodied by and most directly experienced in the Simples of our culture, form the scaffolding for making meaning and for perceptual problem solving as we construct coherence. Because we have learned to expect these structural simples as basic features, even as norms, in what we take to be "sensible tunes," composers can use them as a common base from which to deviate. When they do, they can also assume that these "anomalies"-for instance, a disruption of the metric hierarchy, of a prevailing tonal center, or the introduction of asymmetrical phrase structure and often with it, a prolongation of tension-will be noticed, heard as interesting, complex, and as creating those special, affective moments in the unfolding of a piece.

Thus structural simples serve complementary functions for both the listener and for the composer in their respective work of making meaning: on one hand, structural simples serve to establish a familiar musical universe- they are "norms" generated in and shared by the music that pervades our musical culture; and on the other, structural simples provide the basis for and also the constraints, the limits, within which composers develop the unique complexity of a particular work. Composers, then, do not discard familiar structural simples, replacing them with other components. Complexity, as I am using the term, is instead created as a function of these structural simples. ${ }^{3}$ This will be a recurring 
Visions of Research in Music Education, Vol. 20 [2012], Art. 14

theme in the story of the students' development. (For more on the role of these structural norms, see for example Meyer 1973, Narmour 1977, Lerdahl and Jackendoff 1983, and Gjerdingen 1988.)

I have written this essay in the form of a dialogue between myself and two imaginary college students. I think of the students as typical of those in my MIT classes, and the dialogue as a composite of many that have occurred over the years. I have given the students names that reflect their preferences in hearing rhythms during the earlier days of the class: one, whom I call Met, initially heard rhythms metrically, the other, whom I call Mot, initially heard rhythms motivically (or what I call more generally a figural hearing). ${ }^{4}$ Met is a computer science major who plays the clarinet a little and reads music notation minimally, and Mot is a social studies major who has had no formal music instruction.

I have chosen the dialogue format for several reasons. It was motivated initially as a foil for solving the following problem: once we have developed a particular way of hearing a piece, it is often difficult to make or to imagine a hearing other than one's own, even to consider another's hearing as "possible." Moreover, to make a new hearing is risky since it often requires a fundamental restructuring of the material-re-grouping, making new boundaries, giving priority to different features, perhaps even liberating from the meld, features that were previously left unnoticed, even inaccesible. But simply "telling" another about what you or I might be attending to often fails: entities named may have no referents within the constraints of another's current mental organizers, and relations described may even invoke aspects that undermine the very sense upon which the other depends for the coherence initially made. How, then, could I help readers come to hear in new ways?

This initial foil motivated a second reason for the dialogue format. If we are to help students build on their initial intuitions, we have a responsibility as teachers to respect our students' initial hearings as the powerful base upon which their more complex hearings will develop. Otherwise, we and they end up with a kind of parallel play - two closed systems that collide, bumping up against each other, but never entering into or participating in each other's meaning-making. Through the evolving course of our conversations and our confrontations with one another, I illustrate how the students help me understand the surprises and puzzles they are experiencing. The dialogue, then, serves as an example of how one might explore, probe, appreciate, and try to account for students' initial responses as necessary means for helping students use and go beyond what they know how to do already. Thus, as readers follow the dialogue, they are also following a practice of teaching embodied by the mutual reflection and learning in which all three of us are active participants. Rather than telling the reader about a process of learning to hear in new ways, I ask readers to follow and to participate in the conversation and the moment to moment events that occur in this hypothetical (but possible) story of how Met's and Mot's hearings actually evolve.

In writing the dialogues I suspect I have been influenced by my reading of Galileo's Dialogues on Two New Sciences. Galileo's dialogues with his two students help them to live through the messy, groping, evolution through which new ideas come to be understood and practiced. Unlike more traditional teaching, where the student is presented only with clean, elegant, fully crystalized theories, as if they were as "obvious" to the students as they have become to the teacher, Galileo does not obscure the work, the confusions, the roads taken that seemed to lead nowhere in the course of coming, quite literally, to see (and hear) in new ways. Rather, he engages his student's participation (and through them, the reader's) in the design of questions, problems and hypothetical experimental situations. By letting readers in on the process, Galileo also lets them follow the disequilibrium and the gradual emergence of insights that often accompany such fundamental conceptual and perceptual restructuring. While the dialogues with my two imaginary students are hardly of the same scope or significance, I 
also reenact through these conversations the rocky routes the students travel, and the reader is asked to travel along with us.

The dialogue serves one more function: I use the conversations with Met and Mot as a vehicle for making proposals concerning just what might be an "appropriate hearing," and for speculating on the broader implications that these proposals raise. Of these, the most central is: What are the circumstances that generate fundamental ontological shifts associated with perceptual/conceptual restructuring-how do we ever come to see/hear in a new way?

I imagine our conversation beginning after I have been working with Met and Mot over severaI months. During that time, the students have worked together on their differing hearings of rhythms, in the process coming to appreciate each other's preferences-Mot initially focusing on rhythmic groupings as these form figures, Met focusing on underlying metric units. And we have also spent some time together working through my earlier studies of children's drawing of rhythms, along with the children's construction and invented notations for common tunes - of which "Twinkle Twinkle Little Star" has continued to be the prototypical example. Finally, we have thought a good deal about the set of "structural simples" that these common tunes embody and how these are reflected in various ways by the children's constructions and notations.

This session begins with my suggestion that much of what we have been finding in our work with rather musically impoverished Simples is going to gain musical significance as the students come to hear how Beethoven has used structural simples to create the complexity of the little E-flat minuet. I begin by playing the piece for them. The students' initial reponse leads to my rather too long comments and some initial discussion of complexity itself.

\section{A FIRST HEARING}

JEANNE: First I want to play the Beethoven minuet for you. Just listen to it once all the way through, but without the repeats that Beethoven has indicated in the score.

\section{[PLAYS MINUET, EXAMPLE I]}

MET: I like it, but it sounds pretty ordinary to me; I might even say banal. So where does all this complexity come in?

JEANNE: That's just what we have to find out. In fact, your sense of "ordinary" on first hearing the minuet is going to help rather than hinder in making my point about how Beethoven generates complexity and also the processes through which we come to hear it. I'm going to argue that complexity is a function of structural simples, and that it's in terms of these simples that composers create complexity and that we learn to hear complexity, as well.

MOT: You seem to be suggesting that to make an appropriate hearing of a particular piece is a kind of developmental process in itself.

JEANNE: Indeed I am. Exactly because complex compositions depend on, but are not limited to, familiar structural simples, it is very easy for novice listeners to attend only to what is most familiarthose shared simples - and then to be satisfied that they have gotten from the piece all that there is to get. That's exactly why a complex piece may sound banal, and also why making an appropriate hearing of a complex piece involves developing your hearing so as to go beyond the simples. You see, in a piece of any complexity, composers build in structural simples. That is, they compose those recurring musical relationships shared by the common music of our culture, those that we 

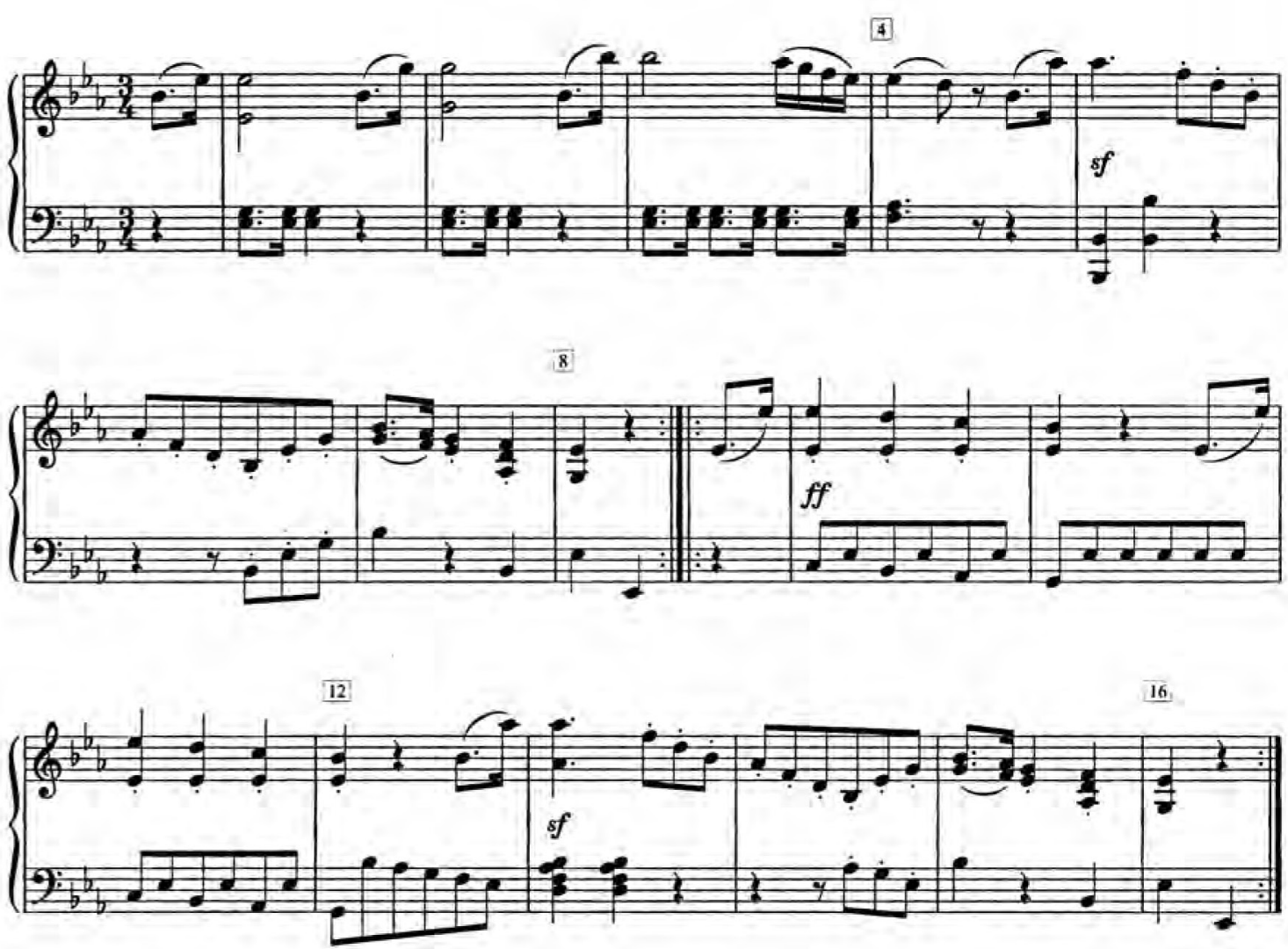

Example 1. Beethoven, Minuet in E-flat, WoO 10/3.

have become familiar with just through listening to the "ordinary" music that is around us everyday. We need the constraints of those common norms as a base from which to understand complexity. For instance, the motives or "germinal ideas" of a given piece may by themselves embody common structural simples, but as the composer develops a piece, his initial motives come to function as if they were unique to that particular piece.

MET: That sounds rather contradictory.

JEANNE: Yes, it's at least paradoxical. The paradox arises because in developing a composition of any complexity, the composer is involved in working out the implications of his germinal musical idea. ${ }^{5}$ And this process, in turn, usually involves transformations of that germinal idea which are specific to it. Thus, even though the germinal motive may be common, or as Met said, banal, the working out is particular to each piece. Indeed, in making these transformations the composer will often reveal to the listener and to the performer, too, features of the germinal idea that most of us would be unlikely to find in it by ourselves. In a way, we learn about the germinal motive through what happens to it within a particular piece. 
MET: Are you saying that there is a mutual process of developing going on? That as the composer, in working out the implications of an initial motive, develops complexity by going beyond the familiar simples built-in to these motives, so listeners, in developing an appropriate hearing of a complex composition, need to go beyond the simples that may be their sole focus in first hearing a work?

JEANNE: Exactly.

MOT: And are you also saying that that is less true of pieces that are just Simples-for instance, our prototypical Simple, "Twinkle Twinkle Little Star"?

JEANNE: That's right. Which points to the more general problem: we need to develop some kind of general strategies for approaching a complex piece that we have never heard before.

MET: I hear what you're saying, and I can relate it to other kinds of learning, too, but I'm not yet convinced that this piece is ever going to sound complex. Where do we go from here?

JEANNE: I'd like to turn that question back to you.

\section{BOUNDARY-MAKING AND ANOTHER SIMPLE}

MET: Actually, I've been thinking a lot about boundary-making. For instance, in all of the studies of children's work with rhythm and melodies, the most interesting events happened at boundary crossings-including the most acute confusions as well as the most surprising insights. In inventing notations for the simple rhythms that you asked children to clap, for example, and also inventing notations for the simple tunes they had built up using the Montessori bells, the children most often got into trouble when crossing a boundary from the end of one motive or phrase to the next. ${ }^{6}$ I've been thinking about why that is so; and that leads me to wonder about what sorts of musical relations generate boundaries in the first place.

MOT: Maybe we could start our mind-changing by listening to the minuet again, paying special attention to the boundaries that we hear.

JEANNE: Good. And in order to help you, I'm going to play just the first section.

MET: I suppose that means up to where you hear the first significant boundary.

JEANNE: Right you are. Listen:

[PLAYS BARS 1-8]

MET: That did seem like a good place to stop.

MOT: And within that section, I think I heard another boundary-marker at about the half-way point, too. If it is the half-way point, then the two shorter phrases within that first section are balanced. So here we have a first example of one of the structural simples we found in analyzing the folk tunes, namely, symmetrical phrase structure.

JEANNE: Absolutely, Mot. Notice anything else?

MOT: Yes, another simple that we identified: the sequence of moves we called the Stability $\rightarrow$ Tension $\rightarrow$ Stability relationship or $S \rightarrow T \rightarrow S r^{7}$ In fact, I think the basic structure of the two first phrases in the minuet may be very close to the structure of the first section of "Twink." In both, the first phrase goes from stability at the beginning to tension at the mid-boundary of the section, while the second phrase starts with tension and resolves it by returning to stability at the end. 
MET: So if we call the two phrases we just heard in the minuet, al and a2, it seems as though the $S \rightarrow T \rightarrow S$ diagram we made for the first two phrases of "Twink" works here, too. And if that's true, I begin to see why the piece sounds banal.

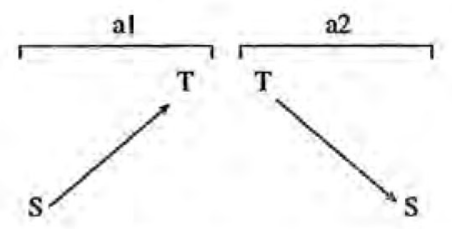

Figure 1. The diagram for "Twink."

мот: But wait a minute, Met. Even though we can hear these simples in the minuet, you'll have to agree that there's much more going on here than in "Twink." "Twink" is only bare bones; and that's why it's the prototypical Simple. Beethoven seems to dress up those bare bones in the minuet: for one thing, he makes an interesting accompaniment. And compared with "Twink," the Beethoven melody is much more varied in pitch and also in thythm-what we called the "surface durations." In fact, I think the contrast between slower and faster motion in the melody helps to create the boundaries.

MET: But longer durations help to create the boundaries in "Twink," too. Maybe that's another common practice for boundary-making, a "norm" we depend on for parsing.

MOT: I think that's true, but your term, "parsing," seems too static. The longer durations feel to me more like arrivals at the goals of on-going movement. And some of the arrivals are tentative, while others are more solid. I suppose that's another way of describing the $\mathrm{S} \rightarrow \mathrm{T} \rightarrow \mathrm{S}$ relationship..

MET: Isn't it interesting how you and I consistently make different descriptions of the same thing?

MOT: I' $m$ more interested in how each of our descriptions reflects the differences in our familiar things to think with-yours coming from the computer world and mine, I suppose, from feelings of myself moving through time and space from one familiar landmark to the next. I'm not so sure we are even describing the "same thing."

MET Maybe not. But I did notice something else about the two phrases and boundary-making: as you hinted earlier, Beethoven makes an accompaniment that varies quite a lot. The accompaniment seems obvious in the first phrase, then it seems to disappear somewhere during the second phrase. That helps to reinforce the distinction between the two phrases, too. Could that change in the accompaniment have something to do with "unique particulars" in this piece?

JEANNE: It's a good beginning, Met. Want to listen again?

$$
\text { [PLAYS BARS 1-8] }
$$

\section{MAKING DISTINCTIONS: DIFFERENTIATING AND COORDINATING}

MET: Listening again, I have the sense that one of the things we're doing is making distinctions or "differentiating." What I mean is that we are pulling apart the various dimensions of the tunemelody, accompaniment, rhythm, pitch. 
JEANNE: That's interesting. I have a strong hunch that learning to differentiate, really to hear distinctions among multiple musical dimensions, is critical to musical development; but the trouble is, that once you have learned to hear these multiple dimensions separately, you're stuck with the problem of learning how to coordinate them.

Мот: It seems to me that in just listening they are pretty much "coordinated" in the first place, so pulling them apart only makes things more difficult.

JEANNE: I get your point; in fact students often tell me that pulling apart these dimensions "spoils the music" for them. But if you will bear with me for awhile, I'd like to help you get a feel for just what sorts of differentiations and coordinations Beethoven makes within the piece itself.

MOT: I suppose that means going into details so we have more to coordinate.

JEANNE: Yes, I guess that's right. For instance, take the $S \rightarrow T \rightarrow S$ relationship in the first phrase of the minuet: just as in the first phrase of "Twink," the $S \rightarrow T \rightarrow S$ moves in the minuet are made manifest through the $\hat{1}-\hat{S}-\hat{1}$ relationship. You remember we made a diagram of "Twink" showing the two phrases, a1 and a2. This diagram showed just the skeleton pitch structure. The "goaltones," shown as whites, are longer, as you said. And we also showed the equal time-spans from î to $\hat{5}$ and back to $\hat{\mathbf{i}}$.

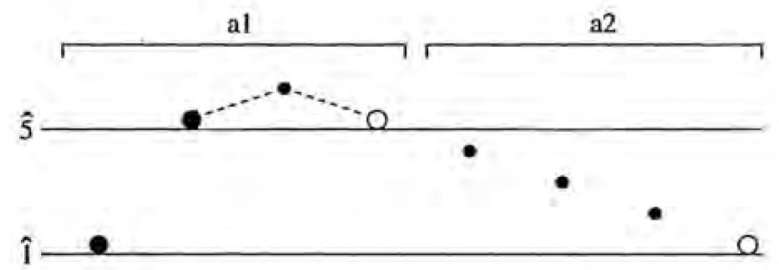

Figure 2. The skeleton pitch structure and the equal time-spans from $\hat{\imath}$ to $\hat{S}$ and back to $\hat{1}$.

MOT: And we included the little prolongation of $\hat{\mathrm{S}}$ in al, as well. The dotted lines showing the prolongation were supposed to reflect our sense that a prolongation was like a rubberband: holding it still at one end, stretching it, and letting it snap back. Of course, that's a fundamentally bad analogy because neither music nor time ever "snaps back."

JEANNE: Good point, Mot. But getting back to the minuet, Beethoven also generates the $S \rightarrow T \rightarrow S$ relationship in his melody by moving from $\hat{1}$ to $\hat{5}$ and back (or should I say, "on") to $\hat{\mathbf{1}}$ again.

MET: More reason why the minuet sounds so ordinary. But, as Mot said before, there must be more going on here. I could hear the $\hat{\mathbf{1}}-\hat{5}-\hat{\mathbf{1}}$ moves in "Twink" since that's practically all there was, but I must admit I can't hear those relations in the minuet.

JEANNE: Let me play just the undecorated skeleton of the first phrase of the Beethoven melody. This will help you to hear that, as in "Twink," the melody goes from the stable tonic, or $\hat{1}$, at the beginning, to $\hat{5}$ at the "top" of the first short phrase. 


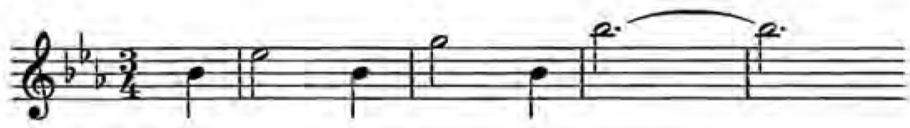

Example 2. Undecorated skeleton of the melody.

MET: I can hear the move from 1̂. $\hat{5}$ quite clearly now. But you made such a big point before of saying that what we hear as $\hat{1}$ isn't a given but rather a relationship that has to be made through the events that happen within the piece, itself. For instance, we noticed that it is the reciprocal relationship between two pitches that, only after the fact, allows us to assign those names, $\hat{\imath}$ or $\hat{5}$.

MOT: You once made an analogy: a dot all by itself as compared with what happens when you add another dot.

JEANNE: Yes. I suggested that a solitary dot all by itself on the page was like a single pitch sounding all by itself; it only holds the potential for meaning. For instance, with respect to defining "a space," a setting in which to make meaning, the dot by itself is insufficient. And in this sense the dot alone, has no meaning.

Then I added another dot:

Now we have a relationship! And as a result of the reciprocity between them we can see and meaningfully talk about, for instance, above and below, inside or outside "their" space, and we can also measure the distance between. And given the two dots, we can make a line joining them, too:

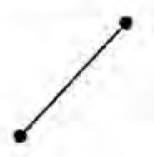

Now we can speak of connectedness in contrast to the previous disconnectedness, or measure the slope of the line and perhaps think about its stability or instability, But none of these relations exists when we have just one dot; these relations depend on the reciprocity between the two dots-each one determines the meaning and the function of the other within the space that they themselves define.

MOT: And then you compared the dots to pitch relations.

JEANNE: Yes. If I play just the first note of the minuet, for instance, it has only a potential for meaning, but like a dot, no inherent meaning. But when I add the next notes, then I have made a particular relationship which is generated by the reciprocity between them. 
MET: I understand that, but it doesn't explain how Beethoven "tells us" what we are supposed to hear as the tonic or $\hat{1}$.

\section{THE GERMINAL MOTIVE AND THE BEGINNINGS OF COMPLEXITY}

JEANNE: It's the little "germinal motive" that does it. Listen to that opening motive in the melody, and you'll hear that Beethoven "tells" us the little universe of pitch and rhythm functions that we can expect to live in:

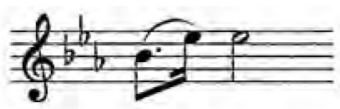

Example 3. Germinal motive.

MET: I can hear, for instance, that the last note sounds more stable than the first, and it also seems to arrive on an accent, a down-beat. But how does Beethoven do that?

JEANNE: The sense of stability you hear on the last note is the result of a coordination among at least the two dimensions you just mentioned-pitch relations and temporal relations. That is, the sense of stability on the last note comes, in part, from the rhythm of the pattern, and in part from the interval between the first pitch and the next two. That interval (an upward 4th) we have learned to hear as having a powerful effect in "announcing," or at least predicting, that the upper pitch is going to be the most stable.

MET: So, are you saying that hearing these distinctions between stability and instability is something we learn, even though we aren't taught?

JEANNE: Yes. And growing up in another culture where distinctions between stability and instability are made, but made differently, you would learn in the same way but not with the same result.

MET: So what about the sense of down-beat or accent?

JEANNE: To say more about that would plunge us into a level of detail that had best wait until you arrive at it yourselves as we go along. Right now, I'd like to shift your focus to an aspect of the piece that is both easier to account for and also one that is unique to this piece. Listen to the first phrase again and notice how Beethoven builds up the whole phrase out of that initial motive:

\section{[PLAYS BARS 1-4]}

MOT: I seem to be hearing the beginning motive several times, but each time it's a little different. And I think I also heard that each successive version of the motive marks the skeleton pitches that you played a minute ago-the pitches that carry the melody from $\hat{i}$ to $\hat{5}$. But there's something not quite ordinary there, already. It seems as if we arrive at 5 before the actual end of the phrase and then Beethoven tacks on some more-a sort of tail. It's as if he is playing with the symmetry: we arrive at the pitch goal of the phrase before the expected time of arrival.

JEANNE: So it won't be a surprise if I tell you that the "tail," as you call it, functions as a prolongation of the 5 . 


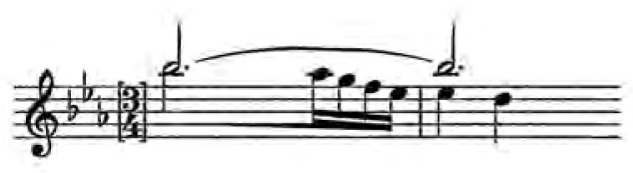

Example 4. "Tail" with 5 sustained.

MET: Does that mean that the so-called "tail" is somewhat like the little prolongation of $\hat{5}$ we heard in the al part of "Twink"? We made a picture of it:

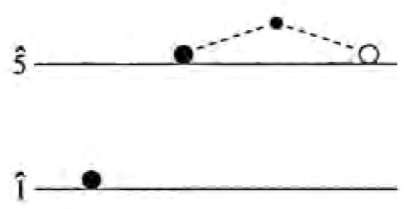

Figure 3. The prolongation of 5 in "Twink."

MOT: But surely what we're hearing in the minuet is a more elaborate prolongation than that one in "Twink," Does that elaboration make for a kind of complexity?

JEANNE: Indeed it does. Beethoven is playing with our familiar structural simples here, just as he is with the other dimensions that you've already mentioned.

MET: I would like to hear the second phrase again, now - where the tension is supposedly resolved.

JEANNE: Sure.

\section{[PLAYS BARS 5-8]}

MET: That's pretty wild! I can hear that the two phrases end "back home," but ...

MOT: Wild, Met? What's happening to all that "ordinary?"

MET: It's changing! I suddenly have no idea what Beethoven is doing in the second phrase. Can you give us some bare bones, again?

JEANNE: Actually, that's a little difficult. I can tell you that hiding in all that "wildness," Beethoven is tracing the familiar path from $\hat{S}$ at the end of the first phrase, down stepwise, $\hat{4}-\hat{3}-\hat{2}-\hat{1}$, to the end of the second phrase.

MET: I believe you, but I certainly don't hear it.

JEANNE: Listen to the second phrase again.

\section{[PLAYS BARS 5-8]}

MOT: You know, I thought I heard something like that $\hat{5}-\hat{4}-\hat{3}-\hat{2}-\hat{1}$ sequence at the very end of the phrase, but it was all bunched up and very fast.

JEANNE: I'll play the phrase again and try to emphasize what I think you're hearing.

[PLAYS BARS 5-8]

MET: Now I heard it, too. And Beethoven helps by the way he changes the accompaniment-the very thing I noticed when we were talking about boundary-making. At the beginning of the second phrase, he leaves the melody all to itself, and then he brings the bass accompaniment back just before that quick rundown to $\hat{\imath}$. Could you play the second phrase once more? 
[PLAYS BARS 5-8]

MOT; I'm beginning to see the value in pulling things apart. In fact, what's fascinating is that once I begin to pull apart and hear the multiple dimensions that Beethoven is working with I also hear that he is using each of them in very special ways. Actually, he seems to be exploiting each of these dimensions to help us hear the underlying simples in the midst of all the complexity.

MET: That suggests that what we are hearing as complex is actually Beethoven's way of making the simples. That seems to be another paradox.

MOT: But if the melody really does go from $\hat{1}-\hat{5}$ in the first phrase, and then fills in the gap, $\hat{4}-\hat{3}-\hat{2}-\hat{1}$, in the second, our diagram for the the first two phrases of "Twink" actually does describe the skeleton structure of this section of the minuet, as well.

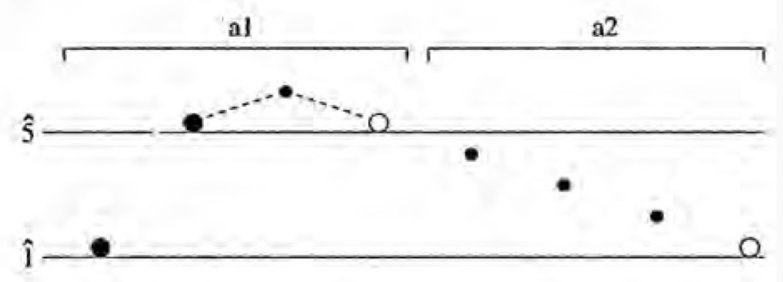

Figure 4. The skeleton structure of the minuet.

MOT: Yes. Except that "Twink," all by itself, is that skeleton: $\hat{\imath}-\hat{5} ; \hat{4}-\hat{3}-\hat{2}-\hat{1}$, with its familiar gap-fill. That's exactly why "Twink" is a Simple and the minuet is not. ${ }^{8}$

\section{A PUZZLE}

MET: $\mathbf{I}$ can hear that quick run, $3 \hat{3}-\hat{4}-\hat{3}-\hat{2}-\hat{1}$, at the end of the second phrase, now, but my question is, what's happening in between the big $\hat{S}$ at the end of the first phrase and that little final flourish at the end of the second?

JEANNE: Before we go any further, let me tell you that in learning to play this piece, I went through a period of puzzlement, too. I heard a surprising relationship, a connection, between some moment early in this first section of the minuet and another moment that happened later. But I couldn't hear exactly where those moments were.

MET: So it was like those experiences you told us about where musicians spontaneously hear in their mind's ear, a similarity or some other kind of connection between two passages that are quite far apart in the straight-ahead chronology of a piece, but they can't always pinpoint the two passages. And when they do, they often can't say right off just what is generating this connection.

JEANNE: Right, Met. And it was in playing the piece over and over again in my mind, searching for the as yet unknown moments and what was connecting them in my hearing, that $I$ found the answer to the question you just asked a minute ago-what happens between the big $\hat{s}$ and the final $\hat{1}$. MOT: Did that discovery change the way you were playing the piece?

JEANNE: Absolutely, Mot. One of the points in trying to make a close hearing of a piece, as we are doing, is to develop a better performance of it-one that projects as much as possible what's going on. And conversely, or maybe reciprocally, tracking the changes made in developing a perfor- 
mance provides good clues to changes in the performer's inner hearing. In fact, this is a perfect example of the continuing interaction between the musical materials of a piece and the performer's performance. As you are playing, the piece "talks back" to you even as you'shape it; and as you experiment, the shaping of it suggests new hearings of the musical relationships.

MET: Now I'm really curious to know what you discovered.

\section{EXPLAINING SOME RHYTHMIC SURPRISES}

JEANNE: To tell you or show you, we need to go back and spend some time with the germinal motive right at the beginning of the piece. Now I'd like you to focus your listening just on the rhythm of that motive. Listen to it again.

[PLAYS GERMINAL MOTIVE]

Could you clap just the rhythm of the motive, Mot?

[MOT CLAPS THE RHYTHM OF THE GERMINAL MOTIVE] ]

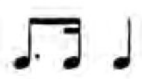

Example 5. Rhythm of the germinal motive.

JEANNE: How would you describe that rhythm, Mot?

MOT: Sort of long-short-long. And it's clearly end-accented. ${ }^{9}$

JEANNE: O.K. Now listen to the accompaniment figure that I'm playing in the bass; and when I'm finished, Met, you clap its rhythm.

[PLAYS BASS FIGURE; MET CLAPS ITS RHYTHM]

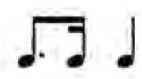

Example 6. Rhythm of the bass figure.

MET: Strange! When I just clap it, the bass rhythm sounds exactly the same as the rhythm Mot clapped for the opening motive in the melody. Let me try clapping one after the other. [MET CLAPS]

MOT: You're right. Now that's a surprise! How come we didn't notice that before? JEANNE: Let me play them as Beethoven wrote them:

\section{[PLAYS BAR I WITH UPBEAT]}

MET: Aha! Now I understand. At least one reason why the rhythms in the melody and bass sound so different is because the germinal motive in the melody is end-accented, as you said, but the figure in the bass is beginning-accented.

MOT: That's it! And that difference in the position of the accent within the same set of durations makes them sound completely different! How does Beethoven do that? 
MET: It seems obvious, now. We already heard that the pitch and duration relationships within the opening motive generate what we heard as an accent at the end of that figure. So when the bass figure comes in, we hear it as beginning-accented because it starts where the opening figure endson the accent.

MOT: And that also helps me understand why we spent so much time on the children's drawings of that rhythm-the one we called the Target Rhythm. ${ }^{10}$

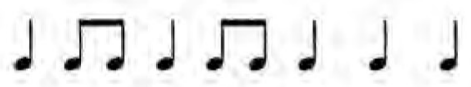

Example 7. The Target Rhythm.

Remember the different groupings that we discovered in the kids' drawings of that rhythm? Jeanne asked the children to make drawings of the rhythm and then afterwards to "put in some numbers that seem to fit." One type of drawing/numbering showed end-accented groupings and another type showed beginning accented groupings.

MET: Yes, I remember one of the drawings and the numberings that went with it. This one was typical of drawings that showed the little inner figures going to the accent.

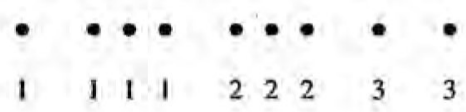

Figure 5. An end-accented grouping for the Target Rhythm.

The groupings were represented by the visual clusterings of the dots and also by the numberings that child added. His strategy was to use the same number within a group (lll 11 ) and then to go to the next number up for each new group $(222 ; 33)$.

MOT: And other drawings showed a beginning-accented grouping. I remember the one where the child counted up within groups $\left(\begin{array}{lll}1 & 2 & 3\end{array}\right)$, then started over again with 1 at the beginning of each new group and counted up again:

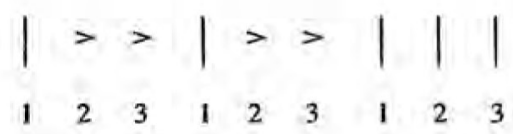

Figure 6. A beginning-accented grouping.

MET: And we also discovered that, even without making any of the claps louder, we hear a metric accent, a regularly recurring stronger beat in contrast to weaker beats, when the faster beats at Level 1 of the metric hierarchy meet up with the slower beats at Level 2.11 In other words, we hear a metric accent when beats are "two-deep" in the metric hierarchy. 


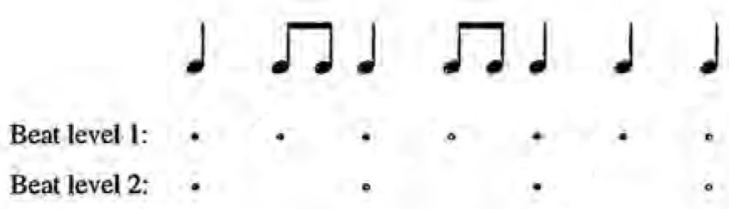

Figure 7. Beats are two-deep in the metric hierarchy.

мот: So when we looked at the Target Rhythm grouped in these two different ways and superimposed the groupings on the metric grid, we could see exactly where the accent falls inside of each figure and how that differs with each hearing.

A

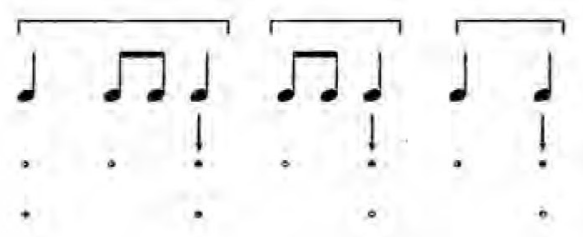

B

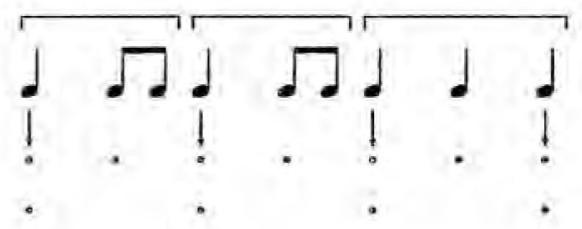

Figure 8. Arrows show exactly where the accent falls in each hearing.

MET: And even though accents occur in the same places in the clapped rhythm, the difference in where the accents occur within groupings makes them sound almost like different rhythms. If we leave aside the first clap, the figures in A always go to the accent; that's why we called the groupings "end-accented." But in B, the groupings (or figures) always kick off from the accent; so they are "beginning-accented."

MOT: Are we saying that as we shift our attention from one grouping to the other, we are fundamentally changing the rhythmic structure?

MET: I suppose. Even though "the rhythm"-the sequence of durations we clap and the position of the accents-is always the same, the changing disposition of the accent within the figures makes a very big difference.

MOT: Now I can understand why that quote from Schoenberg is so important. How did it go?

JEANNE: Schoenberg said, "The way the notes are joined is less important than where the center of gravity comes or the way the center of gravity shifts." 12

MOT: And I suppose that what he meant by "center of gravity" is what we've been calling "accent."

JEANNE: Exactly.

MET: What amazes me is that it's so discombobulating to switch from one hearing of the Target Rhythm to the other. And it's mostly just because the center of gravity shifts. It seems really important. 


\section{A NOTATIONAL INVENTION}

MET: I just thought of a nice way to picture these shifts in the position of the accent within figures. If you mark off the time-span of figures and overlay them onto the metric grid, you'll be able to see a picture of the differences between beginning and end-accented figures. This would be the endaccented grouping we found:

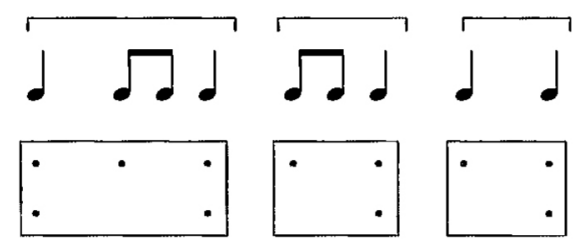

Figure 9. The end-accented grouping.

And the beginning accented grouping would look like this:

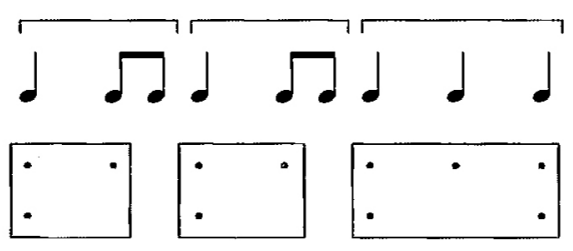

Figure 10. The beginning-accented grouping.

MOT: Now let me make sure I'm getting this. In those boxed, domino-like configurations, the dots at the top show the Level-1 beats in each figure, and the dots underneath show the Level- 2 beats. And where the dots coincide-where they are two-deep, that's where the accent comes within the figure.

MET: Right. Of course, to be precise, both groupings have one figure that includes two accents, but the important differences are still quite clear, I think.

MOT: So a typical end-accented domino for a two-beat figure in contrast to a typical beginning accented domino for a two-beat figure would look like this:

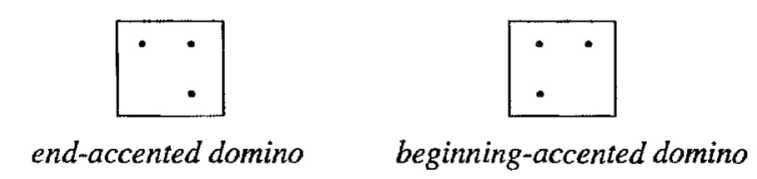

Figure 11. 
MET: You've got it. I like the dominos because they make a kind of notation for showing the intersection between metric structure and figural grouping structure.

MOT: Seeing these kinds of distinctions helps me to understand why the the kids' work with such common rhythms can be relevant to "real music." In trying to make sense of the children's drawings, we had to consider the possibility of hearing a shift in the position of the accent within figures, and we learned to hear how that could make figures sound really different. Now I can hear how Beethoven uses the same trick to develop a single musical "idea"- to make a motive both itself and a variation of itself inside of the same piece. And I also understand now what it means to say that we learn about a germinal motive from what happens to it as the piece goes along-how the composer transforms it.

MET: Except we didn't hear what Beethoven did with the germinal motive until Jeanne played the two versions separately. And furthermore, whatever Beethoven does by way of rhythmically transforming figures must depend on their interaction with a metric grid; and that means generating a metric grid in the first place.

\section{GROUPING AND METER}

JEANNE: Which gets us into the level of detail that I put off at the beginning of our conversation, promising that you would get there yourselves. So, we better stop a minute to hear how Beethoven makes that metric grid and how, as with the other structural simples, Beethoven uses it as a source for building complexity, as well. Let's make a little experiment. I'm going to play a different accompaniment for the first phrase of Beethoven's melody.
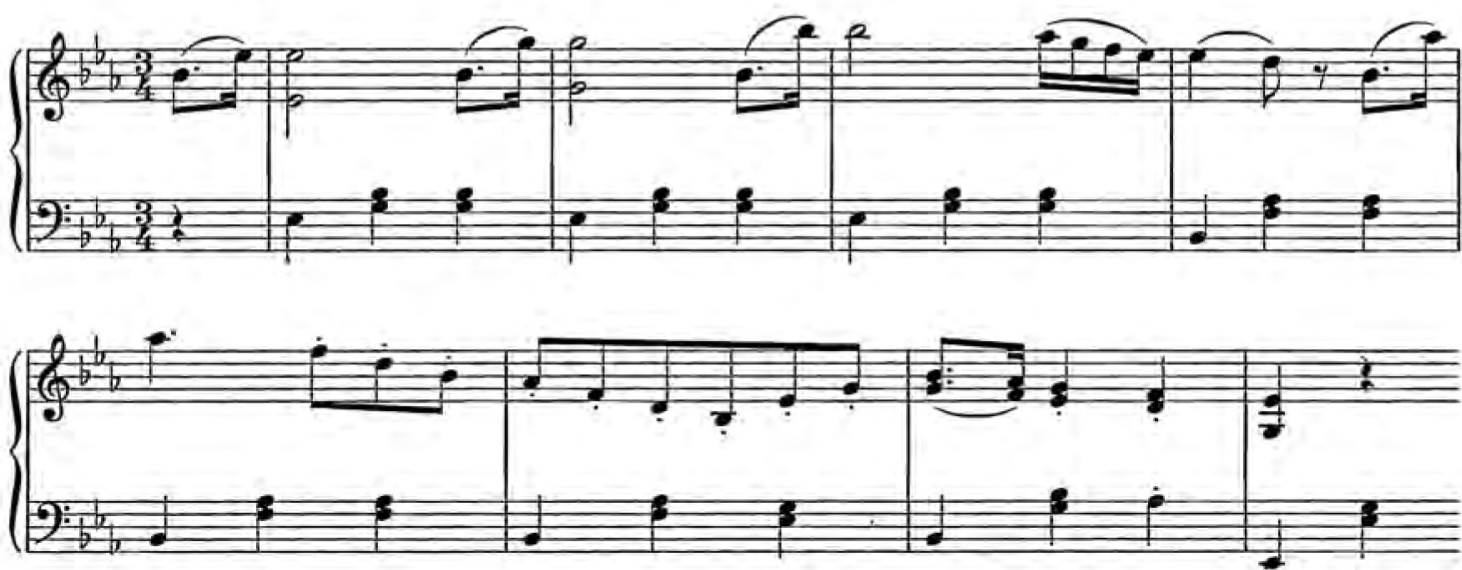

Example 8. New accompaniment for the first phrase.

MET: Now that sounds really banal, like a circus organ or something. And it's obvious that the metric units at both levels of the hierarchy are generated by the alternation between the low bass note and the two upper notes-I mean between the ump and the pah pah. It's banal, but it does "fit" ex actly 
with Beethoven's tune. So I guess the larger metric unit has a 3:1 relationship with the smaller metric unit-or three Level-1 beats to each Level-2 beat.

MOT: Yes, but your accompaniment also makes quite clear what isn't banal in the minuet. Could you play the accompaniment as Beethoven wrote it?

[PLAYS ORIGINAL BARS 1-4]

MET: Actually, your banal accompaniment makes quite clear just how complexity is, indeed, a function of structural simples. For instance, in your made-up rendition, the accompaniment was just a background supporting the melody but with no special relationship to it. You're accompaniment figure is a Simple in itself. I can hear the bare bones of that Simple underlying Beethoven's accompaniment, but the way he creates those "bones" is unique to this composition. He doesn't just take some off-the-shelf figure that's around and lay it on like you did.

JEANNE: So now that you hear that a 3:1 metric grid "fits" as you said, we can at least say that it is a 3:1 metric that Beethoven has generated with his melody. And now your dominos are going to come in very handy, Met. We can use them to see just how figural groupings in both the melody and the accompaniment of the minuet intersect with the underlying 3:1 metric units. That done, we'll also be able to see exactly how Beethoven uses the regularity of the metric and its regularly recurring accent to make complexity.

MET: But there's a problem. I'm still not sure about the time-span of the figures. How many beats are in each of them?

JEANNE: I can understand why you're having a problem. Let me just remind you of something you told Mot when you were arguing over your differing hearings of rhythms. You said, "Time-the beats-keeps right on going and you have to keep right on counting, even though you're not making any clap there."

MET: So are you saying that all the beats have to be accounted for; every beat has to belong to some figure-even where you're not actually playing anything?

JEANNE: Yes, indeed. In fact, accounting for all the beats is very important in performing. The performer needs to hear and feel the flow of the music continuing on even when sustaining a note and even through silence. The silence has to live; it's just as important as the sound. And with that in mind, notice that there is a difference between the way Beethoven notates the melody rhythm and the bass rhythm:

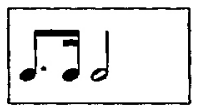

melody

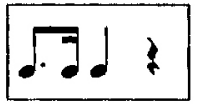

bass

Figure 12.

Mот: So the last note in the melody version is sustained for two beats, and that squiggle in the bass figure stands for where you feel time and the figure going on but you don't actually play anything-what I used to call a "ghost beat?"

JEANNE: Right, Mot. It's a "rest." 
MET: Which, as Humpty Dumpty would say, is a pretty poor name for it since you aren't really resting. But anyhow, it's clear that the two figures take the same amount of time-three beats. And now I understand why the two figures sound the same if you just clap them: you can sustain a note on the piano, but you can't sustain a clap sound; so if you just clap the two figures, they will, of course, sound the same.

мот: "Take the same amount of time," that's a funny expression, too; as if time was some kind of static material that was being boxed and measured; but really it's always going on.

MET: That's existential, Mot; as if there's never any present, or if there is, it's always changing. Sounds like Heraclitus and his river. Anyhow, including the rest-time, the dominos for the two versions would look like this:

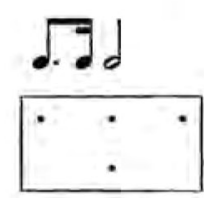

melody

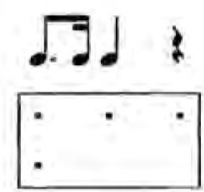

bass

Figure 13.

MOT: That shows the difference in the position of the accent, but we have a new kind of dominomiddle-accented. I thought we agreed that the germinal motive in the melody is end-accented.

MET: That was when we were hearing the figure as having only two beats-before we added the beat that is included in the sustained note. In our original version of the figure it does go to the accent but when we include the sustained note, the figure also continues on after the accent. I guess you could say that the germinal version sort of surrounds the accent-goes to it and ends after it. And the bass figure, the beginning accented version, exactly coincides with the larger metric unit if you include the rest. ${ }^{13}$

мот: How's that, Met?

MET: Well, by definition the larger metric unit always begins with an accent; and because the timespan of the larger metric unit and the time-span of the figure are both three beats, they exactly coincide with each other. Or you could say that the bass figure is contained within the boundaries of the larger metric unit. Maybe you can see it better if we include a little more-let's say two repetitions of each version:

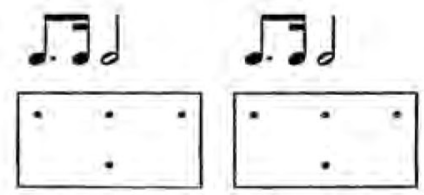

The germinal version surrounds the accent.

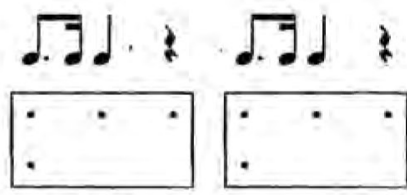

The bass figure exactly coincides with the metric unit.

Figure 14. 
MOT: Now I'd like to see the two figures superimposed on each other as they are played.

MET: Good idea. How about this:

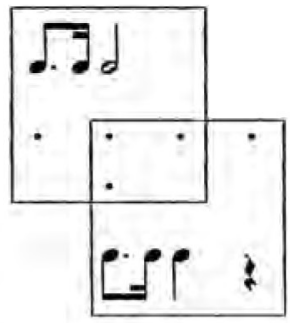

Figure 15. Two figures superimposed on each other.

MOT: Great! It's almost as if the two versions of the motive are having an argument over where the center of gravity lies within the same time-span and within basically the same set of durations.

JEANNE: I like your idea of an argument, Mot. I probably would have called it conflict, but argument is more dynamic - as if something more might come out of this interaction.

MET: It's as if Beethoven slides the motive backwards (or forwards) along the grid while the structure of the grid, itself, stays the same. But we wouldn't be able to hear the motive sliding if Beethoven hadn't made the metric grid clear. I guess that's another example of complexity being a function of the structural simples-assuming now that generating a metric hierarchy is another structural simple.

JEANNE: But do you realize that you appreciate the evolving transformations of the germinal figure and the conflicts they generate only because of the way your mind is able to organize pitch and time? Specifically (with Beethoven's help), you hear the metric structure holding steady while the figures change their relation to that "fixed reference."

MET: And that's coordination! So even though we are still developing our hearing of this piece, our development depends on already having developed those internal mental "organizers" that we have by this time come to take for granted. I suppose that as children, we were developing those mental organizers as part of our general intellectual growth-for instance, learning to keep properties invariant irrespective of context, or to measure events and objects with respect to an appropriate fixed reference. But the paradox is that when we enter a new domain, it seems that we have to develop our capacities to do those things all over again. While I could certainly do that in my own domain - after all, it's essential in math and in designing computer programs, to hold properties constant in spite of change in context-I've had to learn how to do that in new ways in working with musical materials. It's interesting, by the way, that developing these abilities in a new domain has definitely changed my view of what I'm doing in my own world, too.

JEANNE: I'd like to hear more about that. But in the meantime, listen to the first phrase again, and this time pay attention to the figural groupings and how Beethoven transforms them.

[PLAYS BARS 1-4] 


\section{DEVELOPING COMPLEXITY: RHYTHMIC TRANSFORMATIONS}

MOT Listening mostly to the bass, I heard two exact repetitions of the beginning accented accompaniment figure. But then the features that articulated the boundary of the figure, the longer note followed by the rest, simply vanish. The abbreviated motive sounds like it's chasing itself. It goes right on, head over tail, forgetting about catching its breath.

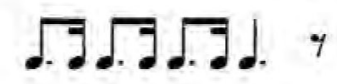

Figure 16. The motive goes right on, head over tail.

MET: I can hear something else. In the process of chasing its tail, the grouping structure of the motive transforms: beginning with an accent as usual, it ends up going to the metric accent and continuing on after it. And the result is that the bass motive turns into the middle-accented original version of the melody.

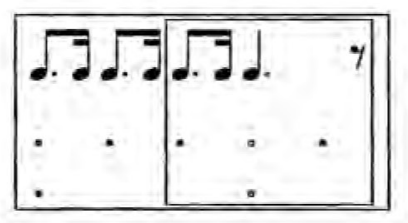

Figure 17. The middle-accented version in the bass.

So while Beethoven first introduces the two different versions of that motive as separate "utterances"- one in the melody and the other in the bass, this time he makes a transformation from one version to the other within just the bass line as it goes along.

MOT: Actually, I was listening to the melody, not the bass, and it goes through a process of transformation, too. I heard the germinal motive twice, but each time moving up in pitch. The third time the motive moved up again and, like the bass, the boundary of the original motive is blurred. But Beethoven does that in a different way in the melody. Instead of abbreviating the motive, like he did in the bass, I think Beethoven extends the last note by tacking on some new material-at least it seems new both rhythmically and in pitch. The effect is that the original motive seems to be stretched. I could sketch the phrase like this:

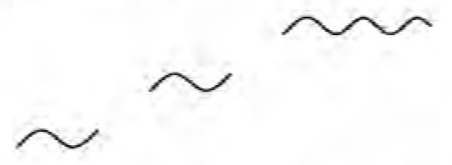

Figure 18. The germinal motive moving up and then stretched. 
MET: That stretched part in the melody where the boundary blurs must be just where the bass motive also gets stretched while chasing its tail.

MOT: Yes, the bass sounds like it's urging the melody onward just where that note is extended.

MET: I'd like to see the actual durations written out along with the metric grid. And let's mark in the boundaries of the figures. too:

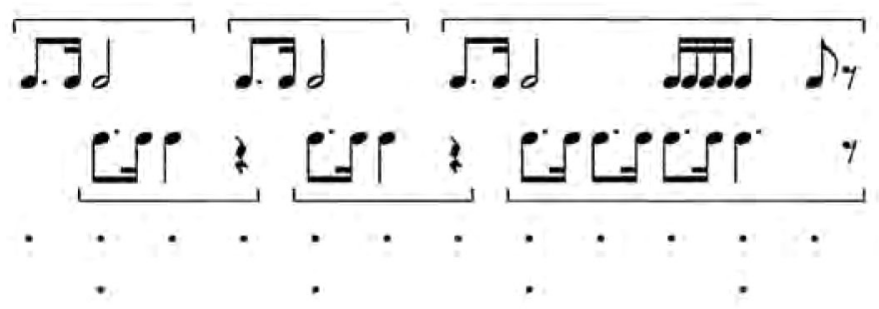

Figure 19. Durations and the boundaries of figures.

MET: Marking in the figural boundaries really shows how the melody and bass figures overlap. And you can also see that Beethoven first clearly announces the two versions of the motive. Each of them is clearly articulated and their time-spans clearly bounded. The subtle rest in the bass helps to mark off the boundaries of the larger figural groups made up of the pairs of contrasting motives-melody and bass. Then Beethoven blurs those smaller boundaries so that the normative time-spans of each motive is extended. Actually the normative time-span is doubled-six beats in comparison with three. And I can also see that the structure of the germinal version wins out. At the end of the phrase, the melody and the accompaniment converge at the accent, and even though both motives are transformed, each in its own way, they both generate, in action, the middleaccented structure of the germinal motive.

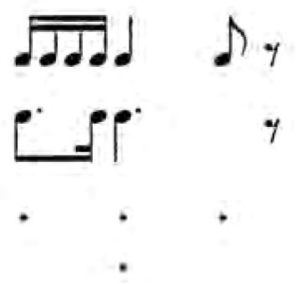

Figure 20. The middle-accented structure of the germinal motive.

MOT: We can also see just what stays the same and what changes. For instance, I initially heard the extension of the germinal motive as new material, a whole new rhythm. But now I can see that, as a middle accented figure, the new material maintains the same underlying rhythmic structure. But I want to say that while I can see the end of that extension as a transformation and sort of hear it, I still hear one single longer figure that goes all the way to the boundary of the phrase. Could you play the melodic extension again?

[PLAYS BARS 3-4] 
MET: So, Beethoven makes a single stretched figure by continuing the pitch transformations of the germinal motive, and then at the end, twice modifying the surface durations of that motive, he still keeps the middle-accented structure intact.

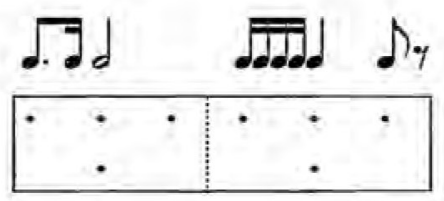

Figure 21. The surface durations modified, the middle-accented structure preserved.

MOT Now I begin to understand what seemed like a contradiction in terms before-the idea that Beethoven sets up relationships that are unique while at the same time making them serve as norms within this piece. These normative structures, such as the middle-accented thythm, function as piece-specific prototypes. Their inner relations are the source of links and also the source for new invention, continuing variation. And these prototypes also set up implications for continuation. For instance, the normative time-span of the germinal motive sets up the implication that that time-span will continue to be realized or, as in this passage, proportionally extended.

MET: These transformations remind me of transformations in geometry, or specifically, topology. Given a particular geometric figure, and keeping its fundamental relations invariant, we consider the group of possible transformations on that figure within the constraints of certain rules. It's called "group theory." But just which transformations Beethoven chooses and when he chooses to make them, helps us to hear the implications of his germinal motive. I suppose that's what you meant, Jeanne, when you said that we learn about the germinal motive by what Beethoven does with it.

JEANNE: That's it.

\section{CONTEXT AND MEANING-MAKING: AN EXPERIMENT}

MOT: So far, we've mostly been paying attention to rhythmic transformations. I'm interested in learning more about pitch transformations and how they go together with rhythmic transformations. Could we go back and talk about that?

JEANNE: Did you notice anything special?

MET: One thing is quite obvious: in the bass you're always playing the same pitch until the very end of the first phrase. In fact, the bass only moves to a new pitch in the process of transforming-when it goes to the accent at the end of the phrase.

JEANNE: I should tell you, by the way, that I'm actually playing two pitches simultaneously in the bass - a little chord. And, as you say, that chord stays put until right at the boundary of the phrase where, on the accent, it goes to a new chord.

$$
\text { [PLAYS BARS 1-4, BASS] }
$$

MOT: Meanwhile, as I said, the melody figure is always moving $u p$ in pitch, both within itself and also from one figure to the next.

MET: Except on its "end run," where the melody plummets down somewhere. But where? 
MOT: It's true; the pitch does turn around and go down. I should fix my picture to show both the upward movement inside of each motive and the turn around at the end:

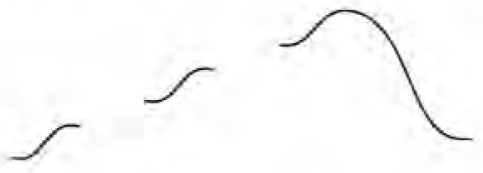

Figure 22. The pitch does turn around and go down.

MET: Do you realize that now your invented picture follows conventions that we see in standard music notation, in graphs, and that the little kids used, too, in their invented notations? You are showing time, left to right, on the horizontal axis and pitch-space on the vertical axis-sort of like a fuzzy, more continuous, graphic version of standard notation. The space-for-time proportions are just about right, too. The motive seems to be literally growing out of itself.

JEANNE: Let's zoom in on that extension. Remember I suggested before that the turn-around in pitch coinciding with the extension of the normative time-span is functionally a prolongation of $\hat{5}$. I mentioned that when we were listening to the whole section and focusing on its underlying pitch skeleton: the end of the first phrase, the half-way point of the first section, marked the tension (T) in the $S \rightarrow T \rightarrow S$ progression. We identifed that relationship as one of the skeleton structural simples shared by so many common tunes. However, by now you've climbed way down the structural ladder to the details that dress that skeleton. Like a blow-up on a map, we've zoomed in on just the small area right around the 3 which generates the tension that is resolved at the end of the first whole section. Now if you keep your attention focused on that detail level, you may hear that there are events in that extension that are quite surprising.

MOT: Are those the surprises you were telling us about before?

JEANNE: No, they aren't, but there is a relationship between that downward swoop and the other surprise-or so I discovered later. But before we get into the tiny details of the plummeting "tail," I feel a responsibility to remind you that we are listening to a very small piece; we're living in a kind of micro-universe.

MOT: But that's very useful; we can really listen to everything that's going on in such a small world. And that includes learning how to climb up and down the rungs of the structural ladder, and to relate our hearings on one level to our hearings on another - or as you put it, relating the details to the larger design.

JEANNE: Actually, it was Roger Sessions who was always emphasizing the importance of relating details to what he called the "long line." In fact, I chose this piece because the musical means Beethoven uses to create complexity on this miniature scale are much like the means he uses in more extended fashion to create complexity in much larger works-such as a piano sonata or a symphony movement.

MET: I guess we're going to have to find that out on our own, later.

JEANNE: That's the idea, Met. Now, about that prolongation of 5 : having used the germinal motive and its transformations to carry the melody of the first phrase from the tonic, $\hat{1}$, to a temporary goal on the 5th scale degree, Beethoven uses those four faster notes, the transformed up-beat, to 
carry the melody back down through the pitch-space it has just traversed. That is, the melody moves stepwise from $\hat{S}$ down to $\hat{1}$, the tonic, and Beethoven repeats that $\hat{1}$ on the accent. But instead of stopping there...

MOT: Wait a minute. I can't hear a return to $\hat{\mathbf{1}}$ at all! At least if we are still supposed to recognize the tonic as the most stable pitch in this pitch universe. That run-down sounds to me like a continuation of the tension we're associating with the prolongation of $\hat{5}$. I hear nothing like a return to stability!

MET: Don't get so upset, Mot.

MOT: Well it's pretty upsetting when you think you've understood something and then you have your assumptions just pulled right out from under you.

JEANNE: Yes, Mot, but that's exactly the essence of significant learning. Some experience or some change in context has to effectively shake up your (often tacit) assumptions before you can even know you have them. And then you have to go through that painful period of queasy chaos where you are both using your assumptions and simultaneously challenging them before you can ever come to see/hear in a new way. In fact this is a great example! And the wonderful thing is that it's Beethoven who is toying with your assumptions, here; without those hidden assumptions, the whole moment would lose its punch. Using them, Beethoven can give multiple meanings and function to the same pitch-property. By musically carrying it over into a new context the same pitch-property takes on the "flavor" of the context in which it is embedded.

MOT: You mean Beethoven forces us to give new meaning to the pitch we were hearing as the stable tonic?

JEANNE: Yes, in a way. But he is able to do that because he can depend on your experienced mental organizers to guide your musical ear. You see, with all the multiple musical dimensions at his command, Beethoven makes them intersect and interact so as to create a new context. This new context gives new meaning to the meanings we had till now been taking for granted. And your response, Mot, gives us on-the-spot evidence that Beethoven has been successful. He can count on his listener's intuitive mental organizers to spontaneously apprehend the new context and the shift in meaning it generates. For instance, recall that the bass, which has been repeating the same pitches all along, finally moves.

MET: But only after working up a head of steam by insistently repeating the shortened version of itself.

JEANNE: Exactly. And remember that that move to new pitches in the bass occurs right on an accent, just at the moment when the previous, beginning accented motive in the bass turns into the middleaccented version of itself.

MOT: Are you telling me that the move in the bass coincides with the accented $\hat{1}$ in the melody, and that's what's giving me such problems?

JEANNE: That's right. It's exactly by making the accented $\hat{\imath}$ in the melody coincide with the move to new pitches in the bass, that Beethoven makes you hear the previously stable tonic as unstable. But, as I keep reminding you, it only works because the well-developed mind behind your musical ear is continuously active, continuously shaping and re-shaping meanings. You also need to know, as I was about to say before Mot got so upset, that the melody continues on past the tonic, ending one step further down on scale degree 7-the so-called "leading tone."

MOT: So that might help to explain why the phrase still sounds unstable at the end.

JEANNE: True. Now, to help you make more explicit all that your silent, mental musical organizers are able to do, let's make a little experiment. I'm going to play around with what happens on that 
problematic accent. First I'm going to play the phrase from the beginning up to and including the final accent where the run-down arrives at the tonic. But this time, I'm going to stop when the melody arrives at the tonic and $l$ 'm not going to move the bass. Listen:

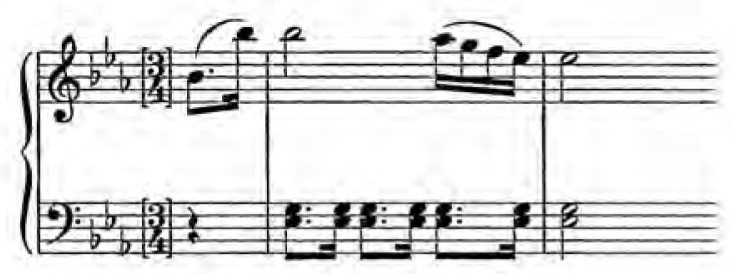

Example 9. Bars 3-4: alteration 1.

MOT: Well, the tonic pitch in the melody certainly sounds stable, now; but as an ending of the phrase it sounds awful, like a shaggy dog story; a big build-up and then the phrase just dies.

MET: That must be another example of how Beethoven creates and uses implications. All that build-up of activity, which seems to intensify just at the boundary, generates implications for some significant move. But in what you just played, all that is thwarted-nothing happens. That's exactly what makes a shaggy-dog story shaggy - the story sets up implications and then just ignores them at the end, just when you're expecting the punchline.

JEANNE: Good. Now I'm going to play the same notes in the melody, stopping on the tonic as I did before. But this time I will move the bass, just as Beethoven has written it.

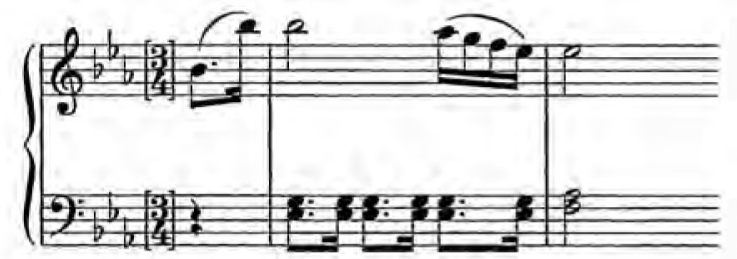

Example 10. Bars 3-4: alteration 2.

MOT: That's amazing. The same pitch as before-or what you're telling me is the same pitch on the accent-sounds almost like a whole different pitch. In the example you played first, I heard the tonic as nice and stable, but as an ending for the phrase, just plain wrong. This time, when you moved the bass, that same tonic pitch sounded anything but stable; it was fighting with what was around it. But, you know, in the context of the whole phrase, that unstable tonic didn't sound all wrong; more like it was eager to move on.

JEANNE: Now one more experiment. This time I'll leave out the accented tonic-I'll run right on through it so that the pitch that the phrase actually ends on, the 7 th degree, will arrive on the accent, together with the accented move in the bass. 


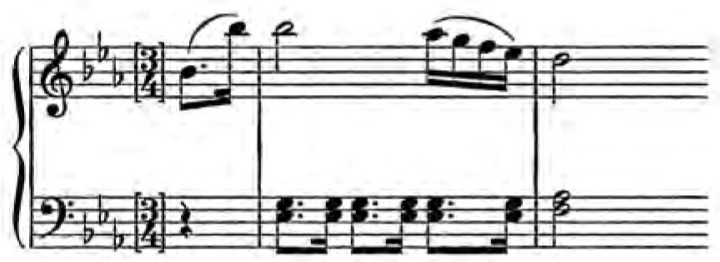

Example 11. Bars 3-4: alteration 3.

MET: Now that sounds perfectly fine. I hear the whole phrase as simply prolonging thentension set up by the previous 5 -reinforcing it, making it more of what it is.

JEANNE: And now, listen to the phrase as Beethoven wrote it.

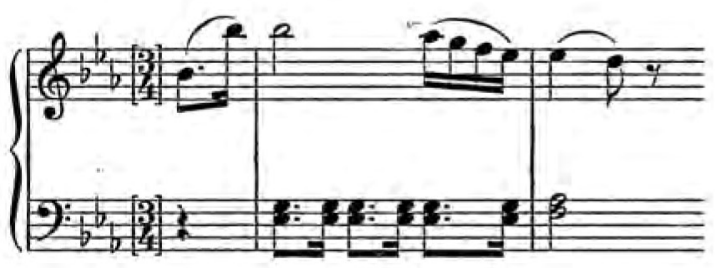

Example 12. Bars 3-4: original version.

мот: That was quite similar to the previous example you played, except now the clash between the melody and the bass, just before the bottom of the downward run, makes the boundary more poignant.

MET: I still hear the run-down as basically a prolongation of 5 , but now I can hear that Beethoven emphasizes that tension by making the bass move to the accented chord while leaving the melody lagging behind on $\hat{1}$. Actually, it's the rhythm, a kind of rhythmic offset, that increases the effect.

мот: So there are two levels of tension: the momentary, fleeting tension generated by the clash between the laggard tonic and the quicker moving bass, and the more extended tension generated by the prolongation of $\hat{3}$.

MET: Your experiment makes me recognize this moment as a glaring example of the power of context to subvert our hearing of same-pitch, and also a perfect instance of how pitch-events can be both the same and different.

МОт: And since we can so clearly hear these differences in function, even when changing such tiny details, it helps to convince me that we are indeed walking around with silent, but actively working mental organizers. But somehow I'm not convinced that these descriptions are describing the work of our silent mental organizers. As I said before, words seem to take apart, to analyze and make discrete, while what I experience seems to be happening all at once.

JEANNE: Yes, Mot, you have put your finger on a problem that I am continually struggling with. It seems to be in the very nature of language to take apart, point to, and name that which we seem to experience all at once, as you said. Even if we propose, for instance, that the yarious elements and 
relations we are able to name, are "interacting," or that our experience of them is at a "higher level of aggregation," we are still talking about experience as if it were made up of separate entities that we are putting together. We talked about differentiating and coordinating earlier in our conversation, but we face the same problems with those terms: coordinating still implies putting together separate elements we have differentiated when, within our immediate experience, those elements as separate entities don't yet exist. So I agree with Mot; in making descriptions we are probably not making explicit what we know how to do in action. Moreover, because of the nature of language, we may be bringing into existence entities that are significantly different in kind from those we experience.

\section{NATURAL KINDS: THE FIGURAL-FORMAL TRANSACTION}

MET: All of which strongly suggests another connection between our process of developing an appropriate hearing of the minuet in all its complexity, and the children's work in building and describing melodies.

MOт: I suppose you're thinking about children's initial figural constructions and notations for melodies and how they evolved into their later formal constructions and notations.

MET: Specifically I was thinking about young Jeff and the differences in the kinds of entities and relations that were reflected in his first construction of "Twinkle" with the Montessori bells and those that were reflected in his later constructions. ${ }^{14}$ Remember that his first strategy was to add new bells cumulatively to his bell-path, next-next-next, in the order that pitch-events occurred in the tune, until he had the whole tune built up. And as a result of that strategy, he needed a new bell for each new pitch-event-not counting the immediately repeated pitches. So his completed bellpath included two pairs of bells that had the same pitch-two G-bells and two C-bells.

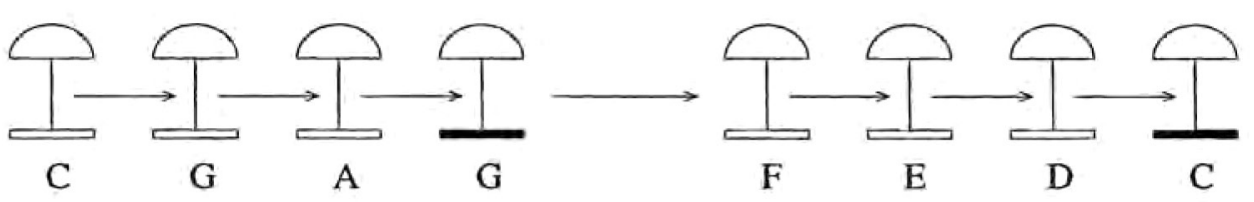

Figure 23. Two G-bells and two C-bells.

MOT: But that's our description of his construction, not Jeff's. Jeff's bell-path seemed to me to reflect the kinds of entities and relations that we experience in real-time as we listen to a piece. For instance, in building the tune, Jeff was going along, following the path of the tune, taking events as they come along. The bells that we name as the same, Jeff heard as different because he was paying attention to just when they occurred in the tune and the function of these events in the context at those moments: he (and we) hear the first G-bell (as we name it) as a "middle"-on the way towards the goal of the first figure, while the second G-bell is an arrival, a landmark along the continuing path. Recognizing invariant pitch properties and giving them a single name seems more like what we are doing, after the fact, when we try to account for our experience. 
MET: We seem to be revisiting our arguments from way back at the beginning of our conversation. But as further evidence of your point that Jeff was paying attention to arrivals and departures, remember that Jeff left a gap, a space between the end of the first figure and the beginning of the second. In fact, this first bell-path made a neat enacted description of the motivic or figural structure of the tune. That's why we called it a "figural" representation. But later on, when Jeanne reduced the set so there was only one bell for each pitch, Jeff went through a period of serious reorganization-much like the "queasy chaos" that Mot was going through a minute ago when the stable tonic pitch turned unstable. In that process, Jeff finally discovered, to his big surprise, that he could use a single bell for two different tune-events. ${ }^{\text {is }}$

MOт: And with that discovery, Jeff was necessarily using a single bell to perform two differing structural functions: the single G-bell now had to function both as middle and as ending within the first figure; and the single $\mathrm{C}$-bell had to function both as a beginning and also as an ending for the whole thing.

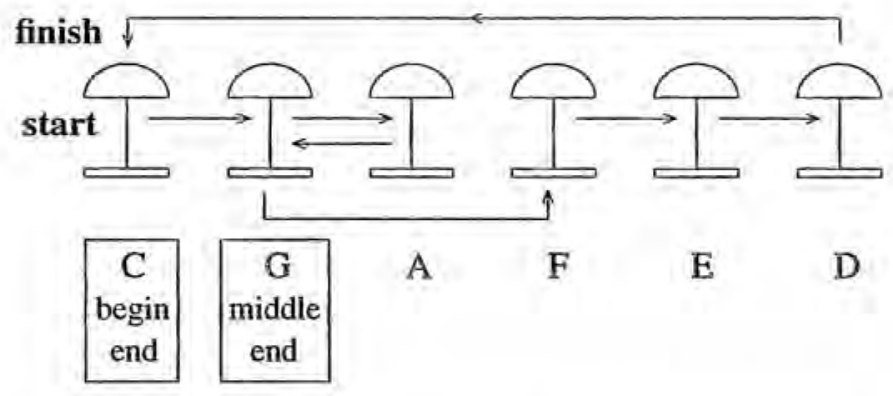

Figure 24. Single bells performing different structural functions.

MET: And in the process, Jeff's action-path had to double back along the bell-path, breaking up what had been a single trajectory - that is, when action-path, bell-path, and sequence of events in the tune had gone along, straight ahead, together. As a result of the new construction, his action-path and the tune ended up just where they began.

MOT: But it was in the third transformation that figural functions got totally lost. I'm thinking of when Jeff learned to build a whole new kind of bell-path with the pitches ordered from low to high. And once built, he learned, after some rather disconcerting moments, to trace the path of the tune events on this pre-built scale.

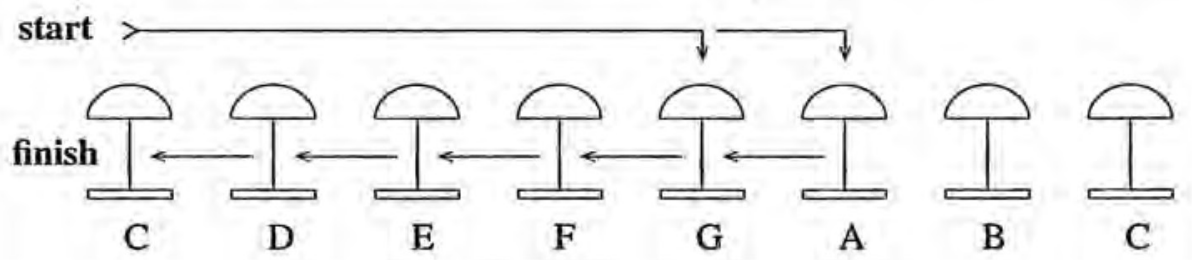

Figure 25. The pitches ordered low to high. 
MET: And he got particularly upset when he first tried to build the tune on this fixed ordering because events which had previously been "close together," in both the temporal sequence of the tune and in space (like the first two events), were now so "far apart." It made us think about how time and space so easily get confounded and how we give each of them quite different meanings as we slip from one context to another.

Events that had been "close together"
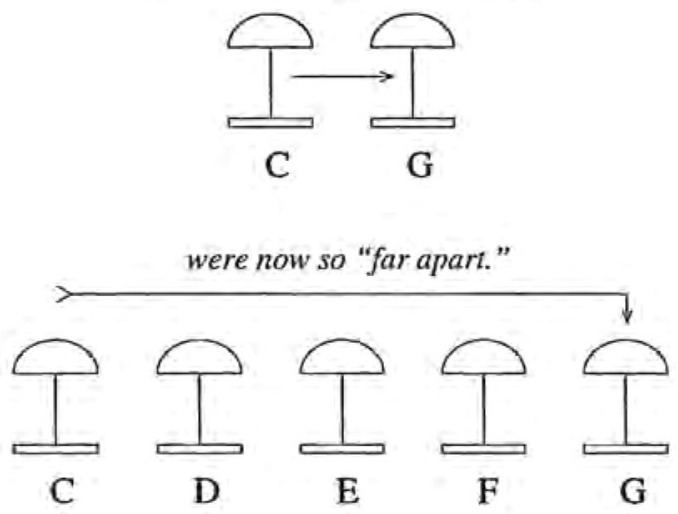

Figure 26.

JEANNE: I should tell you, by the way, that almost all people who have not had any previous music instruction, build a figural bell-path like Jeff's at the beginning of his work. But tune-builders who already play an instrument and have learned to read music notation feel a strong need to begin, as they say, by "putting the bells in order." And that means, of course, building the low-high ordering before they even start to construct the tune.

MET: Are you saying that these educated builders start out at the point Jeff reached only after he had done all the work involved in his various discoveries?

JEANNE: That's right.

MET: I guess that's why we said that Jeff had "progressed" developmentally.

MOT: Maybe so, but what about the fact that in his last constructions he lost the figural structure of the tune and also the changing functions of the same pitch within those figures. Is that progress?

MET: Well, the generalized ordering has a powerful function, too. Think about it: it's only after constructing a fixed reference structure like the low-to-high ordering that we can name pitches invariently across various tunes and contexts. If we couldn't do that, we wouldn't even be able to compare the differing functions of same-pitch, and we wouldn't be able to account for our on-the-spot hearings, either.

JEANNE: The trouble is that once we have thoroughly learned to name properties invariantly and to classify and generalize about the structure of pitch relations, we are tempted to treat names as if they were inherent properties of pitches. And this, in turn, tempts us to obscure the multiple changing meanings a pitch can acquire within the unique story-line of a single melody and certainly within the long narrative of a whole composition. 
MOT: So are you saying that those who have had music instruction, in focusing their attention on invariantly naming and placing pitches in relation to a fixed reference structure, are apt to be inattentive to the unique function of these pitches as the narrative unfolds?

JEANNE: David Lewin was the one who characterized figural constructions as "narrative."16 $\mathrm{He}$ pointed out that, among other things, a narrative or figural construction is importantly different from a pre-built scale construction, especially with respect to the meanings that builders implicitly give to the use of space. In the narrative or figural construction, the positions of bells in space, left to right, "hold" the unique, temporal story-line of events in a particular tune. But in the scale-built construction, the positions of bells in space, left to right, rather than being unique, derive from their generalizable pitch properties. Moreover, this latter ordering does not in any way include time-i.e., it does not represent or embody a temporal sequence. Putting that another way: in a narrative construction, a bell to the right of another bell stands for an event that happens after or later than the bell to its left. In the scale-built construction, a bell to the right of another bell is not an event in time at all; it "comes after" the bell to its left only in the formal sense of higher-than. But I think it would be better not to pit figural and formal hearings against each other; we should consider the relations between them as a continuing transaction. That way we capture the potential for tension between them and also the importance of developing an ability to flip focus back and forth. And that way-we can also include the possibility for hearing events as both the same and different, depending on our focus of attention.

\section{SIMPLES, PRIMITIVES, AND COMPLEXITY}

MOT: But we've strayed from our task of hearing musical complexity-or maybe we haven't. Would it make sense to think of the double meaning that a single pitch acquires in "Twinkle" as a very primitive example of what Beethoven has done in giving the tonic double meaning at the end of the first phrase?

MET: I think so, and "primitive" is an especially apt term if we give it the generative meaning used in math or science-an axiom, a given, that we depend on for developing (or growing) more complex structures. In that sense, Jeff's discovery of double meaning for the pairs of G- and C-bells is a "primitive" which Beethoven uses for developing the more complex double meanings of the tonic at the end of the first phrase. In fact, our experience so far in developing an appropriate hearing of the minuet suggests that the figural-formal transaction is another kind of generative primitive-a potent structural given from which musical complexity develops. All of which reminds me of an issue we have argued about over and over again. You, with your figural persuasion, Mot, wanted to "take things as they come," where things "go together" because they occur inside the same figure, one after the other. And I argued that things "go together" because they share some common property such as same duration or same pitch.

MOT: Yes, and my argument was that to recognize common properties, you have to step off the continuous path of a piece in order to compare events that are distanced from one another in the directly experienced flow of the piece. Remember Alice and the Queens? Alice, thinking figurally, takes days as they come, one at a time, and the Queens, stepping off the temporal sequence of events, take kinds of days or nights together that share a common property-or at least a common name. The White Queen says: 
"We had such a thunder-storm last Tuesday - I mean one of the last set of Tuesdays, you know."

Alice was puzzled. "In our country," she remarked, "there's only one day at a time."

The Red Queen said, "That's a poor thin way of doing things. Now here, we mostly have days and nights two or three at a time, and sometimes in the winter we take as many as five nights together-for warmth, you know."17

MET: So, exactly what is the relevance of all that to the boundary at the end of the first phrase of the minuet?

MOT: It seems pretty obvious to me. If you hear the last accented event in the phrase as different from the very first accented event in the phrase, then you are taking things as they come-the immediately present context determines the meaning you give to the event. But if you hear the first and last accented events as the same, then you're stepping off the time-path of the piece, comparing events that are distanced in time to an outside fixed reference. Removing yourself from the immediately present context, you give meaning to events by classifying - the two events share a common pitch property, irrespective of changing function.

\section{MAKING MULTIPLE MEANINGS; FLIPPING FOCUS}

MET: But the point we seem to be emphasizing is that it's not either/or, but both.

MOT: Which brings me back to our all-at-once experience that seems to be pulled apart, even distorted, by our analysis and the analytic terms it invokes. What are we describing-what we can analytically point to and name, or what we actually experience in listening? For example, in experimenting with the phrase-ending in the minuet, we could hear that the errant tonic really was the tonic when Jeanne didn't move the bass to the new chord. And once she had done that, we were able to hear that it was still the tonic even though she moved the bass-same-pitch, new context, new function. And finally, we could hear when Jeanne really did move to a different pitch. But in making those experiments, Jeanne pulled apart events that are all happening simultaneously in the actual piece.

MET: That depends on what you mean by "simultaneously." In the larger flow of the phrase, these events do seem to happen all at once. But on the small detail level they aren't happening exactly together. We hear the tonic as unstable when for a fleeting moment it's living uncomfortably in the habitat of the new chord in the bass. But immediately afterward, when the melody moves on to its next note, we hear that note as new because, among other things, it lives very comfortably in the habitat generated by the bass chord which has stayed put. That's why in the immediate moment we hear that last note as "resolved," even though on the larger level, the phrase as a whole ends incompletely.

мот: Maybe the big point is that in going so closely into the detailed workings of the minuet, we have actually learned to differentiate between the figural function of an event and its invariant, formal pitch-property. And having learned that, we have also learned to flip our focus from one to the other and to enjoy the musical effect of their convergence. Both same and different, again-or the figural-formal transaction.

MET: That change in what we notice as we move out from the details seems to be another instance of flipping focus, all right, but this time from one structural level to another. In any case, it's also a good example of how the mind can change what the ear beholds. 
JEANNE: I have been concerned that we were going too far into the details of this piece. But what you just said suggests that you are keeping matters in perspective-hearing details as they function in the larger design. Returning to Sessions' point, it's very important in listening to a complex piece and also in performing it to keep clearly in mind that it's the details that generate and carry the larger design, while the larger design gives meaning and shape to the details.

MOT: All these shiftings in our focus of attention-figural/formal, up and down the structural laddereach focus giving different meanings to events, seem to be instances of your favorite subject, Jeanne, multiple hearings and multiple representations of them. And since we seem to be getting better at hearing the multiple meanings that Beethoven gives to pitches and rhythms, I suppose we are also getting on with our musical development if, as you say, the capacity to hear things in multiple ways is a good indicator of developmental growth. But I really want to go on to the next phrase.

MET Before we do, I am reminded that this piece, in all its complexity, seems to be confirming our earlier theory: the greatest activity in all dimensions often occurs at boundaries of phrases or sections. We invented that idea in trying to account for why so many kids in building "Twink" with the bells often got into the biggest troubles at figural boundaries.

MOT: And also where they made the most interesting inventions to extricate themselves from their troubles. ${ }^{18}$

MET: I would put it this way now: a thing, in this case a pitch, can maintain its integrity, its existence, but at the same time it exists differently, has different meaning, in each of the organizing schemes of which it is a constituent. Organizing schemes are like habitats, a thing can live in several habitats and in each it takes on different meaning. And while we might maintain our focus on just one object, one note, that one thing can carry us from one of its habitats to another.

MOT: That sounds like a description of metaphor to me-an object, an event carried over from one organizing context to another, makes you see or hear that object/event in a new way and also influences your view of the contexts themselves. And convergence of activity certainly applies to the boundary of this first phrase in the minuet: the various motivic transformations, extension of the normative time-span, change in the basic direction of the melody from going up to going down while at the same time going nowhere because the big $\hat{S}$ is prolonged. And all of this happening while Beethoven is carrying the tonic pitch over to a new habitat - the organizing context made by the bass chord-where we do indeed hear the tonic in a new way. That's probably why I found it so upsetting at first.

MET: So Beethoven creates that convergence of activity in multiple dimensions as a way of generating the boundary function.

MOT: Yes, but he could have made a boundary without doing all that-like Jeanne did in her made-up versions. What seems to me to be important is that the musical means Beethoven uses work effectively to generate this particular boundary function.

MET And there's that paradox, again: on one hand, all this complex convergence of activity among the multiple dimensions works only because the means Beethoven uses depend on the common cultural norms we have called structural simples. But on the other hand, the boundary conditions are specific to this piece and they are effective because they satisfy the implications of the unique norms that Beethoven has established previously in the process of getting to the boundary. 


\section{HEADING FOR THE END: THE PUZZLE RESOLVED}

JEANNE: We really should move on to the next phrase, and I think we can take care of it quickly since you've done so much work already. I'll play the whole first section so you can put the second phrase in context.

[PLAYS BARS 1-8]

MOT: To recapitulate, it's completely obvious that the second phrase returns to the tonic and to stability. And you told us that it does so by filling the gap between $\hat{\mathbf{l}}$ and $\hat{\mathbf{S}}$, going down stepwise: 4. 3-2. $\hat{1}$. I heard that stepwise progression but, as I said before, only at the very end, all bunched up and very fast.

MET: You also told us that your puzzlement and the subsequent surprising discovery, which I take it happens in this phrase, was related to the ending of the first phrase-the passage that we have so much labored over. Now since that little extension in the first phrase also moves down stepwise from $\hat{5}$ through $\hat{1}$, but spills over the tonic to what you called the "leading tone," I begin to glimpse some kind of connection, here. Could the ending of the first phrase be a kind of underachieving anticipation of the ending of the second phrase?

JEANNE: That's a rather interesting way to put it, and you're right about the basis for my puzzlement. At the time the puzzlement occurred, I described it to myself as hearing a game of catch-up. That final flourish at the end of the second phrase seemed to be somehow joined with, even a part of the first phrase. To test my hunch, I played the whole first section like this:

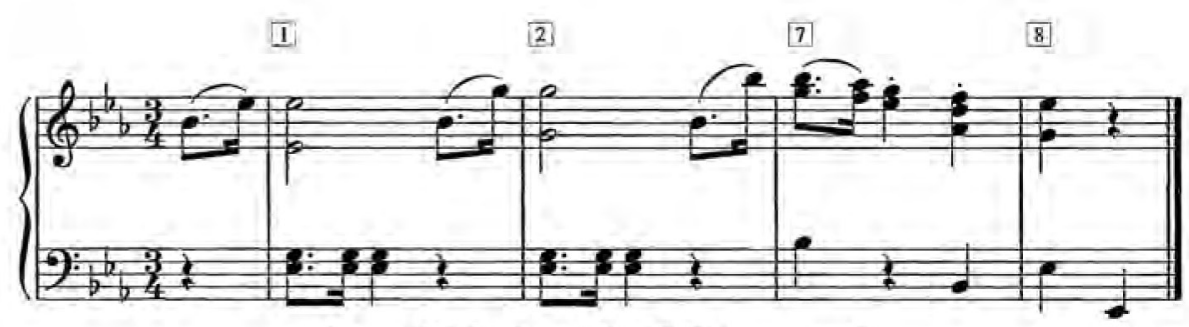

Example 13. Bars $1-2+7-8$. (transposed)

MOT: I think you left out the end of the first phrase, entirely - the motivic transformation and the prolongation of $\hat{5}$-and substituted the end of the second phrase in its place. Or to use Met's language, you substituted the "achieving" downward flourish at the end of the second phrase, for the "under-achieving" downward run at the end of the first phrase. Could you play it again, Jeanne? JEANNE: Sure.

[PLAYS EXAMPLE 13 AGAIN]

MET: Actually you turned the initial arrival of the 5 th degree just before the end of the first phrase into the beginning note of the rushed $\hat{5}-\hat{4} \cdot \hat{3}-\hat{2}-\hat{1}$ ending of the second phrase. JEANNE: Exactly.

MET: But that makes just one, single phrase; you have compressed the whole first section into the timespan of just the first phrase. 
MOT: And was that the connection you were hearing? Because to me it sounds funny-too abrupt, the ending comes much too soon. It's a little like the experiment where you just ended the first phrase on the tonic-the shaggy dog story.

MET: Yes, I agree. In fact, there's something about the ending itself, that seems to want more before it. It needs all that anticipation, all that build-up. I wonder why? Could you play just the ending again, Jeanne?

\section{[PLAYS BARS 7-8]}

MET: Aha! That's very interesting. That final flourish at the end starts with the duration pattern of the germinal motive-long-short-long. But instead of being middle-accented, Beethoven makes it beginning-accented. The melody takes on the structure of the original bass motive! And that beginning accent gives the quick descent a real kick-off.

MOT: I noticed something else: Once the figure is kicked off by the accent, the surface events slow down; in fact, I think they become absolutely regular-each event marking the beat. And that slow down helps to make an ending boundary, too. Could you play it once more and also write out the rhythm of the ending figure in the melody together with the metric grid?

JEANNE: Here it is:

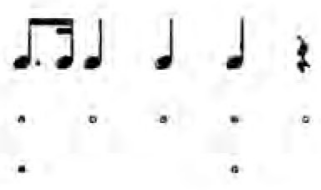

Figure 27. The ending figure.

MET: So we were both right. The figure is beginning accented, and it does go on to just mark the beat as it marches down. Beethoven has invented still another way of transforming the original figures. But wait a minute, we haven't got it quite right. This last transformation is both beginning-and middle-accented. Or maybe it would be more accurate to say that within this single transformation Beethoven merges the accent structures of both melody and bass versions of the motive. Let me try to show what's happening by using my dominos.

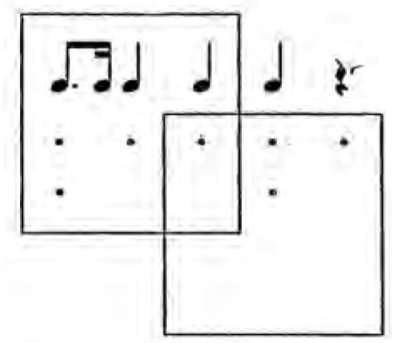

Figure 28. The melody and bass versions merged. 
MOT: That looks very much like the dominos you made to show the melody and bass versions of the motive superimposed on each other, at the very beginning of the piece. Except here, within just the melody, the penultimate event is a member of both kinds of rhythmic structures. You can see it clearly - the last event in the beginning-accented version and the first event in the middleaccented version is captured in that little box made by the overlapping figural boundaries.

MET: What about the accompaniment? I remember that it disappears for awhile, but I think it returns again at the end as another version of the original middle-accented structure. And if that's true, the bass has been thoroughly infected by the melody, just as the melody as been infected by the bass.

JEANNE: Let me add the bass rhythm to Met's dominos.

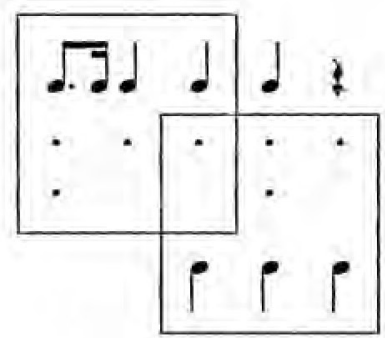

Figure 29. The accompaniment: another version of the middle-accented structure.

MOT: Just three events in the bass, each marking the beat. And in their relation to the metric grid, those three beats reinforce, play out, the middle-accented ending of the melody figure, too

MET: I hear another transformation in the pitch dimension that I would say is pretty important: In every other version of that rhythmic figure in the melody, Beethoven always made a leap up to two repeated pitches. In this last transformation, as we've already noticed, the melody figure goes straight down from $\hat{5}$ to $\hat{1}$. Now I begin to understand why it seemed so abrupt when you tacked this last figure onto the end of the first phrase.

MOT: I don't understand.

MET: It's the issue of implications. Once again at the boundary, we have an increase in activity within and among all the dimensions. But when you just tack on the end of the second phrase to the notquite-end of the first phrase, not enough has happened to prepare us for all the multiple transformations at the end of the section. I need to hear the whole section as Beethoven wrote it. Would you please put the piece back together, Jeanne?

\section{[PLAYS BARS 1-8]}

MET: So a latdoes happen in the part you left out, and it's all those happenings that prepare us for the ending. I think I can now answer my own question about what happens between the big 5 at the end of the first phrase and the $\hat{1}$ at this final ending. First of all, there's the melodic extension, the downard run, at the end of the first phrase; you left that out in you're truncated experiment when you attached the ending of the second phrase to the first phrase. That extension is an important forecast of things to come-implications, again. Then, at the beginning of the second phrase, the accompaniment disappears entirely; the melody just takes off all by itself. It rushes way down 
through the whole pitch-space, considerably expanding the range of the melody so far. And in taking that plunge, the melody forgets about the germinal motive altogether; it's nowhere to be heard. MOT: You're talking as if the piece had taken on a life of its own - "the melody forgets"? Anyhow, I suspect that what you've just described is what we earlier called the "parenthesis," and now I understand why we gave it that name. Beethoven makes it work as a parenthesis by momentarily putting into abeyance most of the musical materials that have carried the piece forward till nowthe germinal motive, the texture with its melody and accompaniment, the normative time-span, and he even overrides the limits of the pitch-range. In short, he takes away many of the norms he has set up as particular to this piece, putting us into momentary limbo. When he brings back the motive, it's like setting us down again in the familiar terrain we left behind at the end of the first phrase. That, it seems to me, is what accounts for Jeanne's sense of "catch-up"-when the motive returns, it's like catching up to where we left off just before the end of the first phrase.

MET: Your rather dramatic rendition makes it very easy to forget that we're listening to a very brief series of musical events, here, not a whole opera.

MOT: Maybe not an opera, but at least a long way from what you heard as "banal" not so long ago.

MET: I have to grant you that.

\section{A CLIFF-HANGER, CATCH-UP, AND AN END RUN}

IEANNE: I only want to add a couple of things to all that you have both been able to hear and describe. Neither of you mentioned the very beginning of the second phrase of the minuet. That's the last time we hear something close to the germinal motive before descending into limbo, as you put it so colorfully, Mot. I hear that large leap at the beginning of the second phrase as a teasing cliffhanger.

$$
\text { [PLAYS BAR 5] }
$$

MET: And what makes a teasing cliff-hanger?

JEANNE: Among other things, Met, that accented pitch in the melody at the top of the leap is the 4th scale degree. Given our internalized structural norms, that move to $\hat{4}$ implies the beginning of a stepwise descent to 1̂. But as you have heard so well, that isn't what Beethoven does. To help you hear what I mean by implication in this case, I'll play the skeleton structure of the section from the beginning decorated only a little with Beethoven's motivic material and accompanied by that Simple-much like my made-up version that Met thought sounded like a circus organ. But this time I'll continue the Simple through the second phrase. See if you can hear the implication inherent in Beethoven's move to 4 ?

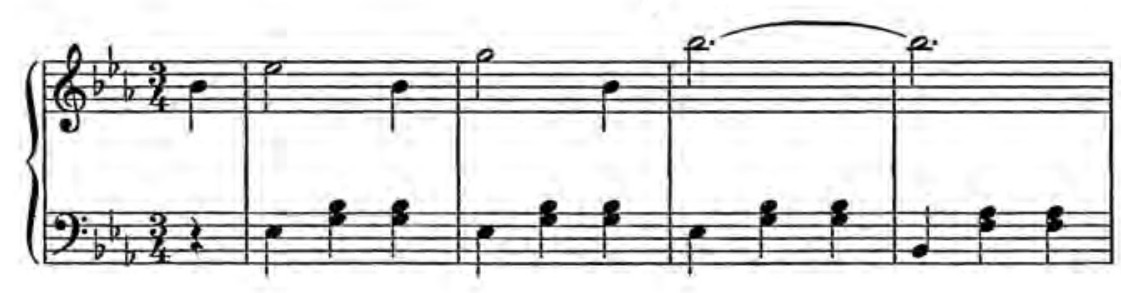




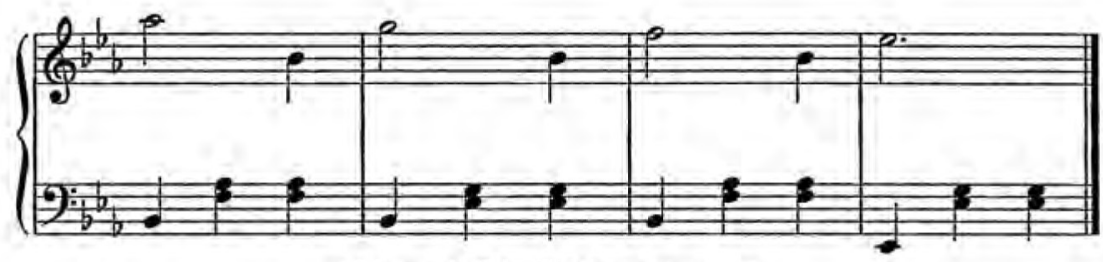

Example 14. Skeleton structure.

MOT: It sounds a lot like "Clementine."

JEANNE: Absolutely, Mot. "Clementine," like "Twink," is another realization of that ever-present structural simple, $\hat{1}-\hat{5} ; \hat{4}-\hat{3}-\hat{2}-\hat{1}$, in two balanced phrases. Furthermore, the motive in "Clementine" is also a little like Beethoven's in the minuet. It also helps that "Clementine" and the minuet are both in triple meter. I'll play "Clementine" so you can hear how right you are. ${ }^{19}$
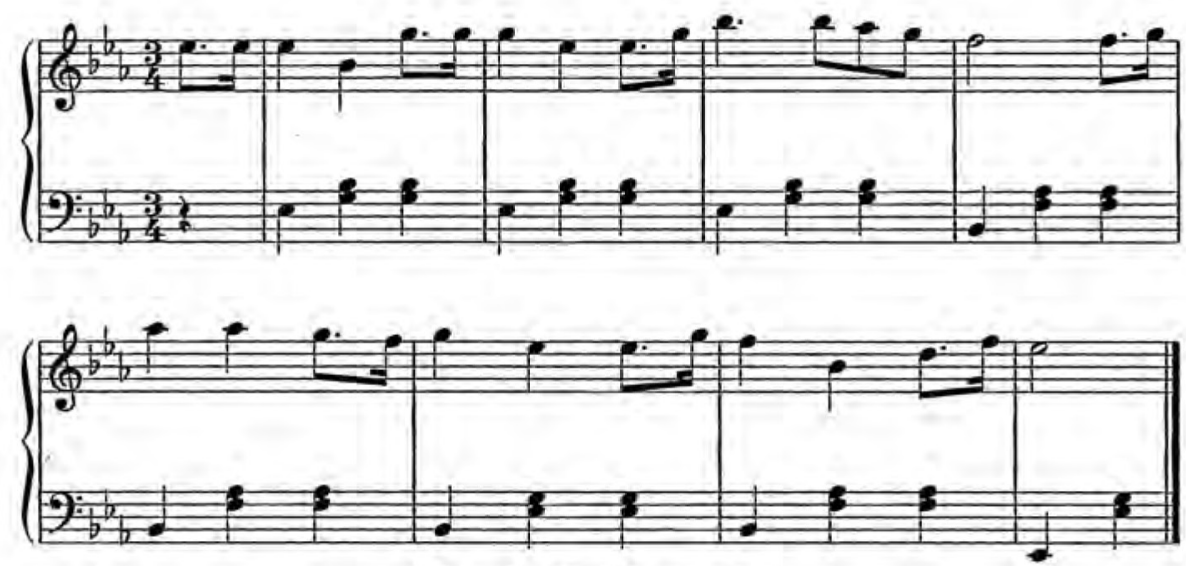

Example 15. "Clementine."

MET: I can hear that $\hat{4}$ as a cliff-hanger now. It sets off the plunge into limbo, but at the same time it seems to hang there, suspended in the air. And something else: when we emerge from the parenthesis, I get this feeling of a "roll-back"; as if Beethoven goes back a step and then makes a second go.

JEANNE: That was actually my "catch-up." Let me put it this way: teasing us with the $\mathbf{4}$ has an effect like putting your toe in the water. But the initial impetus to go on (or in) is diverted in the minuet by the flurry of the parenthesis; the quasi-confusion of the parenthesis is like a hesitation, a delay. The arrival of the familiar motive sounds like a second try-or continuing the swimming analogy, stepping back hoping to make it into the water this time. To create the necessary impetus to go on, Beethoven also takes a step back again to 5 where he left us in the first phrase, and this time he makes it-all the way down to $\hat{1}$ in a single go. 
MOT: But he doesn't really go back to where he left off. Isn't the $\hat{5}$ an octave lower than where he left us precipitously hanging on the $\hat{4}$ ?

JEANNE: You're absolutely right, Mot. And in this way, Beethoven makes it to the tonic an octave below where he left that tonic at the beginning, too.

MET: You told us, Jeanne, that developing a hearing of a complex piece was always a new adventure, but I didn't expect the piece itself to become an adventure. I thought telling stories about music was considered poor taste.

JEANNE: It depends on the stories you tell, Met. But I guess we've all been somewhat carried away. Could you bear to listen just to the end of the first phrase again, and on to the end of the section to see if you hear what I mean. Listen and tell me if my performance projects the stories we've been telling.

[PLAYS BARS 4-8]

MOT: Your performance really helps. Somehow you played the return of the rhythmic motive at the end so that it sounded like a continuation of the $\hat{S}$ just before the end of the first phrase. And you made the under-achieving run-down sound like both an ending and like a preparation. But I could also hear the anticipatory $\hat{4}$ at the beginning of the second phrase trying to make it, but hanging there, subverted as the melody takes off. All that together helped me hear the "roll-back" to 5 which, along with its accented kick-off, sets off the transformed germinal figure, finally carrying the section to its long-delayed and much-anticipated goal.

MET: I think you owe us a performance of the whole piece, Jeanne. We've spent all this time on just the first section and, as it turns out, we couldn't have done it in less. But where does Beethoven take us from here?

JEANNE: Let me put this little bit of music into its natural habitat. I will play the whole piece, now, and with the repeats that Beethoven intends.

[PLAYS WHOLE MINUET]

MOT: The piece seems to have gotten much longer, now that I can hear all its complexity. And I noticed that on the largest level, the whole piece also embodies the structural simple, $S \rightarrow T \rightarrow S:$ an $A$ section which ends stably - that's the part we've spent so much time on; B, which elaborates A and generates more tension; and a return to $\mathrm{A}$ and stability at the end. But, in a way, that fact seems hardly worth mentioning.

MET: No, I think it is worth mentioning because what struck me is that Beethoven even plays with that structural simple in complex ways-at least in comparison with "Twink" which can also be described as A B A. Of course, we wouldn't appreciate what Beethoven has done if we hadn't already thoroughly internalized that Simple with its embodiment of structural simples as a norm. The difference is that there is a return, but the return-or what I suppose you are referring to as the return - doesn't start with a return to the stable beginning of the piecè. Instead, the return begins only with the limbo passage and the anticipatory $\hat{4}$. Furthermore, there's no doubt here about $B$ becoming A; A grows right out of what happens in the middle section. I bet if we didn't know the first section of the piece so well, we would have missed that return altogether.

JEANNE: Actually, many students do miss the beginning of the return, even after several hearings. They hear it as a new passage which somehow ends like the first part. Not so surprising since, as you say, the returning passage is, indeed, in limbo and it's only that final flourish that you really grab onto in the second phrase.

MOT: And something else... 
JEANNE: Let me tell you, Mot, there will always be "something else."

MET: But only if we don't stop with "nothing but," like I was ready to do a while back.

MOT: Which is to say that we have progressed from banal and "nothing but" to complexity, where there seems always to be "something else" to puzzle over.

MET: Maybe that's a fundamental reality test that we have actually gone beyond the simples.

\section{NOTES}

I I find the word decided somewhat problematic here, since even that suggests a more overtly intentional action than I mean to imply with the notion of perceptual problem solving.

2 While I borrow the term conversation from Shahn's remarks, and have used it in a similar way elsewhere (see Bamberger and Schön 1991), I do so now with some hesitation. My hesitation comes from a new recognition that the term may be understood more literally than I (or I think Shahn) intend. That is, readers may too easily, and without consciously intending to do so, take these "conversations" to be mediated by language, "inner language," or at least already in some symbolic form. I believe that this is exactly not the case.

3 To characterize these structural simples is also to characterize a "style," here, the style often referred to as that of the "common practice period." As we move beyond Brahms to the music of the 20th century, we find that composers are indeed replacing many, but not all, of the structural simples to which I am referring. While the result may seem to some as the development of greater musical complexity, it is not necessarily so. Moreover, I am certainly not speaking, here, of complexity in this sense of stylistic change. However, it is probably the case that as composers generate complexity still within the norms of a particular style, they may also contribute to the erosion of the norms themselves.

4 For more on metric and figural hearings, see Bamberger 1991.

5 The term "implication" is borrowed from Meyer 1973 and Narmour 1977 and used here with a similar meaning.

6 See below for more on the Montessori bells, and also Bamberger 1991, pt. 3.

7 The $\mathrm{S} \rightarrow \mathrm{T} \rightarrow \mathrm{S}$ formulation is borrowed from Marx 1852

8 The notion of "gap-fill" as a structural norm is borrowed from Meyer 1973.

9 End-accented, beginning-accented and other similar terms are borrowed from the early seminal work of Cooper and Meyer (1960).

10 For more on the children's drawings of the Target Rhythm, see Bamberger 1991, chap. 5.

11 This schematic notation for the metric hierarchy is reminiscent of that used in Bamberger and Brofsky 1969 and again by Lerdahl and Jackendoff 1983 where the form is as found here.

12 Schoenberg $1975,348$.

13 Those who are used to reading standard music notation may find Met's dominos confusing at first. This is exactly because dominos, as a "notation," describe features that are not included in our conventional notation-specifically, the intersection between figural and metric grouping. In standard notation, for example, the germinal motive would be broken up, visually, by the bar line which precedes the downbeat, marking the beginning of the larger metric unit: 


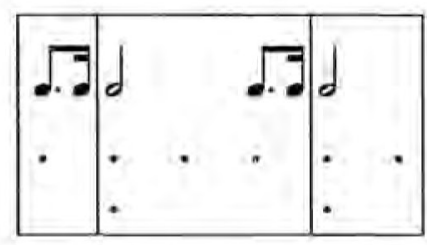

Moreover, adding the bar line gives preference to the metric unit, and in doing so, obscures the characteristic middle-accented structure of the motive. In contrast, the middle-accented structure becomes a distinctive configuration with the domino notation.

14 Jeff was an eight-year-old child I worked with over a period of six months. During that time, he built and rebuilt "Twinkle" many times using the Montessori bells and also invented a series of notations for playing it on the bells; see Bamberger 1991. (These bells are not handbells. Mushroom-shaped, they are attached to columns which are in turn attached to wooden bases. They stand on a table, and can be moved around; they are played by being struck with a little mallet.)

15 See Bamberger 1991, pt. 3, and Lewin 1993.

16 See Lewin 1993.

17 Carroll 1960, 324.

18 For more on this, see Bamberger 1991.

19 I am grateful to Fred Lerdahl for pointing out this similarity.

\section{REFERENCES}

Bamberger, J. 1991. The Mind Behind the Musical Ear: How Children Develop Musical Intelligence. Cambridge, MA: Harvard University Press.

Bamberger, J., and H. Brofsky. 1988. The Art of Listening: Developing Musical Perception. New York: Harper and Row.

Bamberger, J., and D. A. Schön. 1991. "Learning as Reflective Conyersation With Materials." In Research and Reflexivity, ed. F. Steier. London: Sage Publications.

Carroll, L. 1960. The Annotated Alice: Alice's Adventures in Wonderland and Through the Looking Glass. Edited by M. Gardner. New York: Clarkson N. Potter.

Cooper, G., and L. B. Meyer. 1960. The Rhythmic Structure of Music. Chicago: University of Chicago Press.

Gjerdingen, R. O. 1988. A Classic Turn of Phrase: Music and the Psychology of Convention. Philadelphia: University of Pennsylvania Press.

Lerdahl, F., and R. Jackendoff. 1983. A Generative Theory of Tonal Music. Cambridge, MA: Massachusetts Institute of Technology Press.

Lewin, D. 1993. Musical Form and Transformation. New Haven: Yale University Press.

Marx, A. B. 1852. Theory and Practice of Musical Composition. Edited and translated by H. Saroni. New York: F. J. Huntington and Mason \& Law.

Meyer, L.B. 1973. Explaining Music: Essays and Explorations. Berkeley: University of California Press.

Narmour, E. 1977. Beyond Schenkerism: The Need for Alternatives in Music Analysis. Chicago: University of Chicago Press.

Rosenfield, Israel. 1989. The Invention of Memory: A New View of the Brain. New York: Basic Books.

Shahn, B. 1957. The Shape of Content. Cambridge, MA: Harvard University Press.

Schoenberg, A. [1975] 1985. Style and Idea: Selected Writings of Arnold Schoenberg. Edited by L. Stein. Reprint, Berkeley: University of California Press. 